
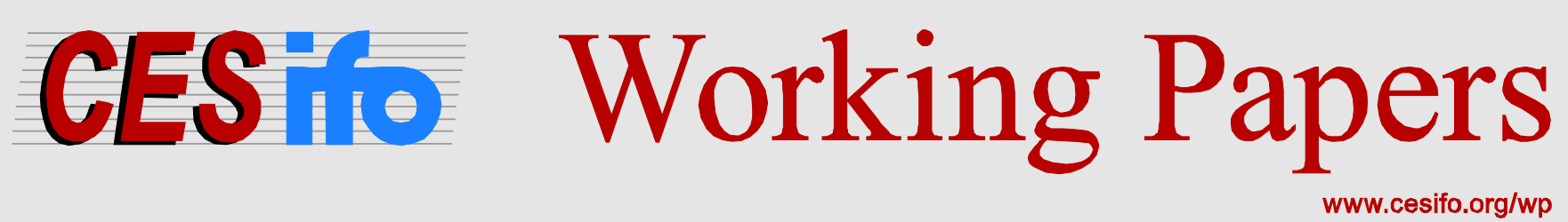

\title{
Profit Shifting and FDI Restrictions
}

\author{
Mathilde Lebrand
}

\author{
CESIFO WORKING PAPER NO. 5885 \\ CATEgORy 8: TRAde Policy \\ MAY 2016
}

An electronic version of the paper may be downloaded

- from the SSRN website:

- from the RePEc website:

- from the CESifo website:

wWw.SSRN.com

www.RePEc.org

www.CESifo-group.org/wp 


\title{
Profit Shifting and FDI Restrictions
}

\begin{abstract}
Tariffs have almost completely disappeared but various restrictions on foreign entry remain for multinationals. Many trade agreements and Bilateral Investment Treaties (BITs) have been signed to lower tariffs and reduce the risks of expropriation. Why do we see so few agreements removing FDI entry barriers? Could the contemporary rise of tax havens where multinationals can shift their profits explain the absence of FDI agreements? In this paper I develop a model in which governments can restrict the entry of foreign affiliates and multinationals can shift their profits across countries. I first demonstrate that the possibility for multinationals to repatriate their profits is a determinant of FDI restrictions. An agreement can solve for the resulting inefficiency. However, I show that an agreement is made unnecessary when (i) there is foreign lobbying that pushes for more entry, or when (ii) firms can shift profits to tax havens. Tax treaties that reduce profit shifting would be a first step towards more agreements that reduce FDI restrictions. I conclude by providing empirical evidence that profit shifting affects the choice of FDI restrictions.
\end{abstract}

JEL-Codes: F230, D430, D720, F130.

Keywords: FDI, multinationals, investment agreements, lobby, profit shifting.

\author{
Mathilde Lebrand \\ European University Institute \\ Via Roccettini, 9 \\ Italy - 50014 San Domenico di Fiesole FI \\ mathilde.lebrand@eui.eu
}

May 1, 2016

I am very grateful to Paola Conconi, Piero Gottardi and Bernard Hoekman for continued guidance. For helpful feedback, I thank Alessandro Barattieri, Matteo Fiorini, Lionel Fontagné, Andrei Levchenko, Julien Martin, Peter Neary, Andres Rodriguez-Clare, Immo Schott, and seminars participants at Midwest Trade Conference Penn State, ETSG Paris, CESifo Conference on Global Economy, Georgetown, Warsaw Dissettle Workshop, University of Montreal, Montreal Political Economy group, and EUI. 


\section{Introduction}

Tariffs have almost completely disappeared but various Foreign Direct Investment restrictions remain for multinationals (OECD 2010). A large number of trade agreements and Bilateral Investment Treaties (BITs) have been signed whereas few agreements aim at reducing barriers to FDI. FDI is not covered by the WTO and BITs only deal with the risks once a multinational has established. Only $2 \%$ of BITs have a chapter on entry restrictions. Why do we see so few agreements removing FDI restrictions? Could the contemporary rise of tax havens where multinationals can shift their profits explain the absence of FDI agreements? While the determinants of tariffs and of trade agreements have been largely studied, there is little analysis of the determinants of FDI restrictions and of investment agreements. I focus on investment agreements that reduce (ex-ante) FDI restrictions whereas most existing investment agreements focus on (ex-post) equitable treatment and expropriation protection once the multinational firm has entered.

In this paper I first study the economic and political determinants of FDI restrictions. The repatriation of profits by multinationals is the main economic determinant of FDI restrictions. This leads governments that do not cooperate to choose inefficient barriers to FDI. An investment agreement can then help them to commit to efficient policies and lower FDI restrictions. However we observe that very few investment agreements to reduce these barriers have been signed. This paper provides two arguments to explain why (i) some countries have lowered their barriers without signing an agreement and why (ii) some countries have kept high barriers and do not want to sign such agreements. In order to understand these facts, I add two additional features: a political dimension where lobbies can give contributions and a tax haven where part of the profits can be shifted. Lobbying by foreign multinationals to counteract lobbying by domestic firms can explain unilateral reforms to remove barriers to FDI without signing agreements. The presence of a tax haven where firms shift their profits removes the gains from cooperation and makes non-cooperative policies efficient. FDI restrictions remain and investment agreements become unnecessary.

I proceed in four steps. First I build a model to study the economic and political determinants of FDI restrictions. Governments choose whether to restrict the entry of foreign affiliates and multinationals can shift their profits across borders. Domestic markets suffer from imperfect competition and FDI policies are a substitute for domestic reforms to liberalize by allowing more foreign firms to enter and compete with domestic firms. I define the non-cooperative game between the two governments and find an economic rationale for foreign entry restrictions. Foreign affiliates decrease domestic firms' profits and relocate their profits abroad. However the profits from foreign sales that are repatriated and finally benefit domestic consumers are not taken into account when governments decide their policies. These policies are inefficient and agreements that implement the cooperative outcome could allow countries to implement the efficient outcome. It is therefore surprising to observe that very few investment agreements to reduce (ex-ante) FDI restrictions have been signed. I need to complement the model with additional features.

In a second part I look at the political dimension of the policy choice. I allow both domestic 
firms and foreign affiliates to give contributions to the government. There are two main contributions in this part. First I contribute to the literature on lobbying and trade policies by providing a deeper analysis of the role of foreign lobbies and their interaction with domestic lobbies. Second I consider a bargaining game with more than two agents and use the "coalitional bargaining equilibrium" definition of Compte and Jehiel (2010) to study the outcome when the government and more than one lobby bargain. The policy outcome depends whether the government and all lobbies participate in the bargaining process or not. Sub-coalitions between the government and one lobby only can form and affect the policy decision. I consider the size of the coalition as endogenous and study the conditions under which each sub-coalition emerges. I then show that lobbying by foreign firms can implement the outcome of an agreement under certain restrictions. For an agreement to be redundant, there are three conditions: (i) the foreign lobby should be part of the decision coalition, (ii) profits' repatriation should be sufficiently low, and (iii) governments should sufficiently value foreign contributions compared to domestic contributions. This explains why some countries liberalize and reduce their FDI restrictions without signing agreements.

Third I consider the addition of a tax haven where firms can locate part of their profits. A tax haven is an isolated location without consumers nor producers. The repatriation of profits from one country to another does not take place any more. Part of the profits disappear in the tax haven. Non-cooperative entry policies are now efficient and the gains from cooperation that explain the need for agreements disappear. This explains why some countries choose high barriers and do not want to negotiate agreements. Tax agreements that reduce the role of profit shifting to tax havens are expected to be a first step towards more investment agreements.

I conclude by providing empirical evidence that profits repatriation affects the level of FDI restrictions. I use two datasets that quantify restrictions: the OECD index of FDI restrictions and the World Bank index of foreign restrictions in the services sector. I build two proxies for the multinationals' behavior: a weighted index of corporate tax rates and a weighted index of growth rates. I show that they significantly affect the level of restrictions. When studying both OECD and non-OECD countries, I show that corporate tax rates and growth opportunities in the host country are complement. Lower corporate tax rates only lead to higher policies if growth opportunities are expected.

I contribute first to the literature on trade policies and trade agreements. Motives behind tariffs and trade agreements have been extensively studied through the terms-of-trade literature (Johnson (1953-54), Grossman and Helpman (1995), Bagwell and Staiger (1999)) and the commitment literature (Maggi and Rodriguez-Clare (1998, 2007)). More recently Ossa (2011) build on the Krugman 'new trade' model to show that countries impose inefficiently high tariffs in order to attract firms to locate and increase employment.Mrazova $(2009,2011)$ use oligopolistic models and show that profit-shifting from the foreign firms towards the domestic firms is a rationale for protectionism. I use a similar oligopolistic model to study the impact of consumer's taste for variety and firms' repatriation on FDI restrictions. Blanchard (2010) shows that international ownership can mitigate the reasons why countries choose inefficient policies such that a trade agreement can become unnecessary. In my paper I study direct barriers to FDI rather than tariffs and the role of investment agreements rather than trade agreements. To my knowledge, I am 
among the first to fully study the determinants of FDI entry barriers. Compared to traditional models on tariffs, my paper on horizontal FDIs allows to study non-tradable services or goods facing prohibitive tariffs. Previous papers on the terms-of-trade motive do not cover the case of non-tradable services whose trade had been growing in the last decades. It also brings the possibility for multinationals to choose where profits are redistributed. In the case of exports, all profits benefit owners in the country of origin. In the case of FDIs, it is more complicated and the location of profits becomes a political parameter for governments when choosing FDI policies. Similarly to previous works, profit shifting is a determinant for trade barriers but it here happens inside multinationals that relocate profits from their affiliates towards the parents.

Lobbying as a determinant for trade policies and agreements has been extensively studied (Maggi and Rodriguez-Clare (1998, 2007), Grossman and Helpman (1994), Gawande et al. $(2012))^{1}$ but few papers focus on foreign lobbying. Several papers (Conconi (2003), Antràs and Padró i Miquel (2011), Aidt and Hwang (2008) and Aidt and Hwang (2014)) have highlighted the positive role of foreign influence on trade policies. Compared to the others Antràs and Padró i Miquel (2011) develops a political model with a voting mechanism and considers government to government pressures instead of a foreign lobbying channel. Empirical papers have shown the positive impact of foreign lobbying on trade barriers in the US (Gawande et al. (2006)) and on tourism and development in the Caribbean (Gawande et al. (2009)). In my paper I derive the conditions under which foreign lobbying can make an agreement unnecessary by pushing for more entry. Another contribution of the paper is to consider endogenous sub-coalitions between some lobbies and the government. ${ }^{2}$ Compared to Maggi and Rodriguez-Clare (1998), bargaining with more than two players is more difficult to model. I use the concept of "coalition bargaining equilibrium" from Compte and Jehiel (2010) and study the possible outcomes depending on which coalition emerges from the game.

Finally I discuss the effects of the presence of tax havens and tax agreements on FDI. Evidence of a positive effect has proven elusive (Blonigen and Davies (2001), di Giovanni (2005), Davies (2004), Blonigen and Davies (2004), Blonigen et al. (2014)). In this paper I study the effect of profit shifting on FDI policies rather than on FDI flows. Profit shifting through transfer pricing has been shown to mainly benefit a few tax havens (Davies et al. (2014), Vicard (2015), Zucman (2014)). I show that the existence of tax havens lead to high FDI barriers and few agreements to reduce these barriers. Tax treaties that curb the few main tax havens or make transfer pricing very expensive are shown to reduce FDI barriers and make agreements more likely.

The paper is organized in four parts. After detailing the model, I first describe the noncooperative game between the two countries when governments simultaneously choose their polices through a bargaining game with their lobbies. Then I discuss whether an agreement is necessary when foreign lobbying pushes for more entry. I then consider the possibility for firms to shift profits towards tax havens through transfer pricing. Finally the last part provides empirical evidence that higher profit shifting affects foreign restrictions.

\footnotetext{
${ }^{1}$ Compared to Grossman and Helpman (1994) I show that governments might prefer an agreement over lobbying. Compared to Maggi and Rodriguez-Clare (1998, 2007), lobbying can do better than agreement because of the presence of foreign lobbying.

${ }^{2}$ In the paper I do not tackle the issue of lobby formation and the free-rider problem like Bombardini (2008). Considering that foreign affiliates and domestic firms can both form a lobby, I focus on the issue of endogenous sub-coalitions between the government and one lobby only.
} 


\section{$2 \quad$ A model of foreign entry restrictions}

I consider two countries, Home and Foreign $\left({ }^{*}\right)$, that have symmetric economic and political structures. I now describe the economic and political systems of country Home in detail.

\subsection{Preferences, technology and industry equilibrium}

Preferences Demand functions are identical across countries. There are $M$ firms that produce one good each in country Home. No exports are allowed here and the final number of firms that produce is here determined by the FDI policy. The representative consumer of country Home has a quasilinear-quadratic utility function of the form:

$$
\mathbb{U}\left(q_{0}, \bar{q}\right)=q_{0}+A Q-\frac{\delta}{2} Q^{2}-\frac{1-\delta}{2} \sum_{i=1}^{M} q_{i}^{2}
$$

where A is a positive constant, $q_{i}$ is the consumption of firm $i$ 's product, $\bar{q}=\left(q_{1}, \ldots, q_{M}\right)$ is Home's consumption vector, $Q$ is the aggregate consumption $\left(Q=\sum_{i=1}^{M} q_{i}\right)$ and $q_{0}$ is Home consumption of the numeraire good. The parameter $\delta$ is the substitution index between goods which ranges from 0 to 1 . Consumers decreasingly value variety for higher value of the substitution index. When $\delta=0$ goods are independent and consumers value a balanced consumption bundle. When $\delta=1$ goods are homogenous and consumers do not care about variety. Maximizing utility, the inverse demand for firm i's good is

$$
p_{i}=A-(1-\delta) q_{i}-\delta Q
$$

with $q_{i}$ the consumption of firm $i$ 's good and $Q$ the aggregate consumption of all firms' goods.

Technology This paper looks at horizontal FDIs and greenflield investment. Foreign multinationals can set up an affiliate in country Home to start producing and access foreign markets ${ }^{3}$. The objective of multinationals is only to sell to foreign consumers and not to re-import intermediate goods. For simplicity we assume either that tariffs or other trade costs are prohibitive or that the product is non-tradable. There are two types of firms that produce in country Home: domestic firms and foreign multinationals. All firms are assumed to have identical production capacity. There is no additional cost for a multinational to open an affiliate abroad. Once the multinational has been allowed to enter the country to produce, there is no cost difference between a domestic firm and a foreign affiliate. All products have the same price. There is a total number of firms $M$ from which $M_{n}$ are domestic firms and the rest $M_{f}=M-M_{n}$ are affiliates from Foreign firms. In the rest of the paper I focus on the short-term equilibrium and assume that the number $M_{n}$ of domestic firms is exogenous. I use the model of trade with oligopoly used in Mrazova (2011) which is an adaptation of Yi's (1996) extension of the Brander (1981) model. Compared to Mrazova (2011), I allow the number of firms and therefore individual profits to vary according to the government's policy. The consumer's utility depends on both the price and

\footnotetext{
${ }^{3}$ Horizontal FDI can substitute or complement cross-broder exports or be the main mode of provision for non-tradable goods and services. The "non-tradability" of services has been quantified by Jensen (2011) who uses the location of firms and their distance to consumers in the US to build such an index.
} 
the number of varieties. Strategic interactions between firms depends on the substitution index $\delta$ : the higher $\delta$, the more direct is the competition between firms.

Each firm, either a domestic firm or a foreign affiliate, produces an individual quantity $q(M)$ and the total production is given by $Q=M \times q(M)$. All firms produce with constant returns to scale at the same marginal cost $z$ in terms of the numeraire good. All firms are similar and solve $\max _{q} \pi=(p-z) q$. The first-order condition is

$$
p-z-q=0
$$

In the Cournot equilibrium,

$$
p=\frac{A+z(1+\delta(M-1))}{2+\delta(M-1)} \quad \text { and } \quad q=\frac{A-z}{2+\delta(M-1)}
$$

Prices and individual quantities are decreasing in the total number of firms and the substitution index.

Repatriation of profits A main difference between a model with exports and a model with horizontal FDIs is the possibility or not for firms to choose where to locate their profits. When firms access foreign markets through horizontal FDIs they can leave part of their foreign sales' profits abroad and repatriate the rest of these profits. Therefore the location where profits are redistributed is the first crucial difference between domestic and foreign affiliates in the Home country. Domestic Home firms redistribute all their profits from domestic sales to Home consumers whereas foreign affiliates only redistribute part of their profits to Home consumers. The other part is repatriated in the country of origin and benefits Foreign consumers. The repatriation of profits can happen for several reasons: intra-firm trade, return on equity or tax optimization. A large part of profits repatriation is explained by transfers of rights to intellectual property or of other similar intangibles. For example, this covers the provision of non-tradable services such as insurance, hotels, restaurants and retail for which a licence is required from the parent. Other intangible goods are managerial oversight and planning, marketing knowhow, or R\&D capital. Atalay et al. (2014)) shows that transfers of intangible goods rather than transfers of goods along the production chain can explain a large part of vertical integration. They find that surprisingly one-half of upstream establishments report no intra-firm shipments to downstream establishments. In this paper we consider firms that all produce a similar good and intra-firm trade is limited to transfers of intangibles.

The frontier between repatriation of profits due to transfer of intangibles and profit shifting for other reasons is thin. The literature on profit shifting lists three main methods to shift profits: (i) contribution of equity or allocation of debts towards affiliates in low-tax countries, (ii) tax inversion through the acquisition of a foreign firm that allows the initial firm to move its headquarter in a low-tax country ${ }^{4}$, and (iii) transfer pricing ${ }^{5}$. In this part i model the case

\footnotetext{
${ }^{4}$ Tax inversion is especially used by American firms to avoid paying taxes on all their activities. They acquire and merge with a firm in a low-tax country and relocate their headquarters there. High US tax rates still apply to US earnings but not to profits overseas. This differs from cross-border mergers done for strategic business purposes.

${ }^{5}$ This technique allows firms to shift profits by choosing the pricing of goods and services sold between affiliates.
} 
of transfers of intangibles inside the firm for which multinationals set a price that does not need to reflect their real cost. Here transfer pricing allows firms to shift profits. Whereas transfer pricing is regulated and should not be used to transfer profits across borders, the enforcement of an arm's length price for intangibles is a real challenge for tax administrations. Similar transfers of intangibles rarely occur in the market and comparable transfers are difficult. Property rights are risky assets that are difficult to assess. We model the repatriation of profits as a pricing decision for an intangible that has to be bought from the parent firm.

I denote by $\phi$ the fixed amount per unit of sales that is repatriated. It is similar to a higher unit cost for the foreign affiliate but is not considered as such a cost when choosing its price. This parameter is chosen by the headquarter of the multinational to relocate profits or not. A higher $\phi$ results in more relocation of profits towards the country of origin. I do not explicitly model the pricing choice by multinationals ${ }^{6}$.

The domestic profit of a Home firm that is fully redistributed to Home consumers is

$$
\pi(M)=(P(M)-z) q(M)=\left(\frac{A-z}{2+\delta(M-1)}\right)^{2}
$$

with $q(M)$ the production per firm when there are M producers and $P(M)$ the price of the good in the Home country. They all depend on the number of firms producing in the country.

The share of a Home affiliate's profit from sales abroad that is redistributed at Home is

$$
\pi^{r e p}\left(M^{*}\right)=(\phi-z) q^{*}\left(M^{*}\right)=\frac{(\phi-z)(A-z)}{2+\delta\left(M^{*}-1\right)}
$$

with $q^{*}\left(M^{*}\right)$ the production per firm and $P\left(M^{*}\right)$ the price given the number $M^{*}$ of producers in the Foreign country.

The profit of a Foreign affiliate from sales at Home that is redistributed in the Home country is

$$
\pi^{* f}(M)=\left(P(M)-\phi^{*}\right) q(M)=\frac{\left[\left(A-\phi^{*}\right)+\left(z-\phi^{*}\right)(1+\delta(M-1))\right][A-z]}{(2+\delta(M-1))^{2}}
$$

with $\phi^{*}$ the parameter that defines the profits relocation behavior of a foreign affiliate.

The share of the profits made by a Home affiliate abroad that is redistributed in the Foreign country is

$$
\pi^{f}\left(M^{*}\right)=\left(P^{*}\left(M^{*}\right)-\phi\right) q^{*}\left(M^{*}\right)=\frac{\left[(A-\phi)+(z-\phi)\left(1+\delta\left(M^{*}-1\right)\right)\right][A-z]}{\left(2+\delta\left(M^{*}-1\right)\right)^{2}}
$$

with $q^{*}\left(M^{*}\right)$ the individual production per firm in the Foreign country and $P^{*}\left(M^{*}\right)$ the price given the policy $M^{*}$ in the Foreign country.

Figure 2.1 represents the profits that are redistributed at Home. Domestic firms leave all their profits at Home, Home parents get a share of the sales from their affiliates abroad, and

\footnotetext{
The legal price should be the price of the same goods and services paid by an unrelated party.

${ }^{6}$ In the empirical section I detail more the determinants of profit relocation. The level of corporate taxes and the existence or not of treaties about double taxation can affect the level of repatriated profits. The presence of tax havens also affects the level of profits that is redistributed in the host country. Finally growth opportunities (growth rates) in the host country lead foreign affiliates to reinvest part of these profits to benefit from the future economic opportunities and to relocate less back in their country of origin.
} 
Foreign affiliates redistribute part of their profits in the host country.

Figure 1: Profits redistributed at Home

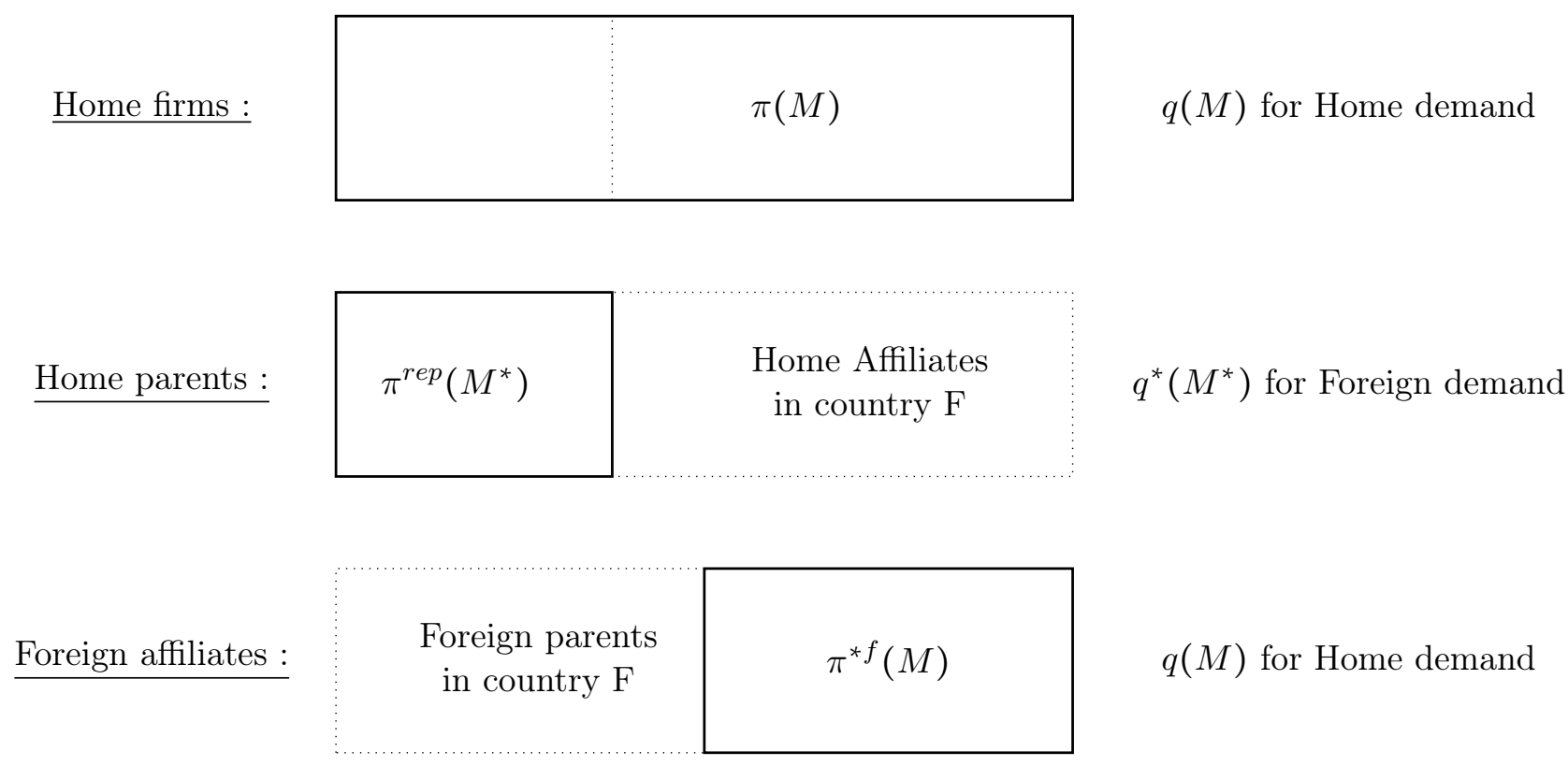

The location of profits by multinationals creates a difference between domestic firms and foreign affiliates. All firms have the same individual production, sell at a same price but do not redistribute the same amount of profits at Home.

For the rest of the paper I assume $M_{n}=M_{n}^{*}$ and $\phi=\phi^{*}$.

The FDI policy The only policy instrument of the government is a market access restriction in the production sector. The government chooses the number of foreign firms that can enter and directly compete with domestic producers. More precisely, the government takes as given the number of domestic firms $M_{n}$ and sets a value for the total number of producers (including domestic and foreign firms) $M$ which directly determines the number of foreign affiliates allowed to produce in the country $\left(M-M_{n}\right)$. This is a model without firm entry such that the additional firms are foreign affiliates that start producing in the Home country. This can be interpreted as a model with a short-term perspective or a model with a sector in which entry costs are prohibitive. The only instrument the government can use to lower the frictions form imperfect competition is the FDI policy. A restrictive policy means that few additional foreign firms start competing with domestic firms whereas a liberal policy means that many foreign firms start producing.

The entry of foreign firms is a key channel to liberalize markets, especially in services sectors in which FDI is a major mode of market access. Several papers show that a key channel to explain why liberalization reforms improve the offer of services is the entry of foreign firms. Arnold et al. (2011) highlight that foreign entry in services sectors is the key channel to improve performance in the manufacturing sectors. The positive role of foreign entrants in other sectors was shown by Javorcik et al. (2008) and Fernandes and Paunov (2012). ${ }^{7}$

\footnotetext{
${ }^{7}$ In Arnold et al. (2011), Foreign firms bring know-how and knowledge about new products. Their presence
} 


\subsection{The political game}

I now introduce the possibility for firms to form lobbies and exert an influence on the government.

\subsubsection{The lobbies}

I assume that firms are able to coalesce in a lobby in order to affect the FDI policy chosen by the government. I assume that there are two lobbies in each country, the lobby of domestic firms ("the domestic lobby") and the lobby of foreign affiliates ("the foreign lobby"). Each lobby can give contributions to the government at the time when the government chooses the FDI policy. The domestic and foreign lobbies have different objective functions.

The domestic lobby's objective is given by:

$$
L(M, c)=M_{n} \pi(M)-c
$$

with $c$ its contribution to the government. Domestic firms value protection against foreign entry at Home. Indeed a higher number of total firms $M$ producing at Home implies a lower price and therefore a lower profit for domestic firms at Home $\left(\frac{d \pi(M)}{d M}<0\right)$. The domestic lobby gives contributions in order to increase the restrictions on foreign entry and lower the choice of the final number $M$.

The foreign lobby's objective is given by:

$$
L^{f}\left(M, c^{f}\right)=\left(M-M_{n}\right) \pi^{* f}(M)-c^{f}
$$

with $c^{f}$ its contribution to the government. On the contrary, foreign affiliates might give contributions to either lower or increase protection. More entry increases the number of foreign affiliates (extensive margin). However individual affiliates' profits decrease in the number of total firms $M$ (intensive margin). The foreign lobby maximizes the sum of all foreign affiliates' profits that might be decreasing in the number of firms if individual profits decrease too quickly. This can happen when the government wants a lot of new foreign firms to enter in order to lower the frictions from the imperfect competition framework or when the domestic lobby is weak. The Foreign lobby either pushes towards more protection in the same direction as domestic firms or values more foreign entry ${ }^{8}$.

Lower barriers are preferred by the lobby of foreign firms if the gains from an additional entry

may also lead domestic providers to improve the quality of their products. Javorcik et al. (2008) focus on the Mexican detergent industry and find that the entry of Walmart reduced the distribution cost for detergent manufacturers. Fernandes and Paunov (2012) studies the impact of FDI inflows in producer service sectors on the productivity of Chilean manufacturing firms. They find that foreign direct investment in the services industries fosters innovation activities in manufacturing. This model does not assume any productivity differences between the domestic and foreign firms but suggests that policies restricting foreign entry are central to liberalize some sectors, especially those for which products are non-tradable.

${ }^{8}$ Other intuitions that are not explicitly modeled are the following. Foreign firms do not enter a foreign market at the same time. Multinationals that enter first lobby value more restrictions whereas those that are among the last want to decrease restrictions to enter the market. The presence of conflicting interests is here represented by a foreign lobby that maximizes the aggregate profit of all potential affiliates. The lobby pushes for more entry when an additional entry creates more than the sum of the individual loses due to the decreasing profit. On the contrary it pushes for less entry if the sum of the individual loses is higher than one more entry. 
are higher than the loses :

$$
\underbrace{\pi^{* f}(M)}_{\text {extensive margin }} \geq-\underbrace{\left(M-M_{n}\right) \pi^{* f^{\prime}}(M)}_{\text {intensive margin }}
$$

\subsubsection{The government}

The government chooses the FDI policy, i.e. the number of total firms, and whether to bargain with the two lobbies or not. When there is no lobby, the government maximizes the utility of the consumer. The social welfare is given by

$$
W\left(M, M^{*}\right)=C S(M)+\underbrace{\widetilde{\Pi}\left(M, M^{*}\right)}_{\text {national PS }}+\underbrace{\Pi^{* f}(M)}_{\text {foreign affiliates' PS }}
$$

The producer surpluses are the profits that are redistributed to the domestic consumer. The profits from domestic sales that are repatriated are redistributed to the foreign consumer and do not enter the social welfare $W . \widetilde{\Pi}\left(M, M^{*}\right)$ denotes the sum of the profits from the domestic sales of the $M_{n}$ domestic firms and the repatriated profits from the foreign sales of their affiliates abroad $\left(\widetilde{\Pi}\left(M, M^{*}\right)=M_{n} \pi(M)+\left(M^{*}-M_{n}^{*}\right) \pi^{r e p}\left(M^{*}\right)\right) . \Pi^{f *}(M)$ denotes the aggregate profits of the foreign affiliates that are not repatriated $\left(\Pi^{f \star}(M)=\left(M-M_{n}\right) \pi^{\star f}(M)\right)$.

Following Grossman and Helpman (1994), I assume that the government differently values the domestic social welfare and the political contributions. An additional difference between domestic firms and foreign affiliates is introduced here. The first difference comes from the location of redistributed profits that differs between domestic firms and foreign affiliates. A second difference is introduced in the political game. I assume an aversion towards foreign influence. Following Gawande et al. (2006), I model this aversion by a government's valuation of contributions that differs across lobbies. Formal rules can restrict contributions from foreign entities $^{9}$. Such contributions might also be perceived as running against domestic interests ${ }^{10}$. The aversion of policy-makers towards foreign contributions can be micro-founded through a probability for the government to be punished by the voters if they discover the existence of foreign contributions. However there exists only poorly documented evidence about the effect of foreign lobbying on governments' choices. When $\gamma=0$, foreign lobbying is considered as forbidden or totally inefficient. When instead $\gamma=1$, foreign contributions are perfectly valued by the government, i.e. there is no difference in valuation between domestic and foreign contributions.

\footnotetext{
${ }^{9}$ For example the regulations in 1938 and in 1966 were passed by the Congress in the United-States to restrict and ban foreign lobbying are well explained in Corrado et al. (1997) that study the foreign influence in the United States. Limits on foreign political contributions started in 1938 in order to prevent Nazi money from influencing the political debate. Congress passed the Foreign Agent Registration Act that required agents of foreign entities engaged in "political propaganda" to register and disclose their activities. Later on, bans on political contributions in any US election by any foreign government, political party, corporation, or individual were passed. Nowadays all lobbying expenditures have to be registered and the country of origin is to be mentioned according to the Lobbying Disclosure Act.

${ }^{10}$ For example, a few years ago Alibaba hired a very influential lobbying firm when planning for a potential takeover bid for Yahoo. The news was largely covered in the media and the coverage showed a certain suspicion around lobbying from Chinese firms (cf article in the New York Times, "Alibaba Taps Lobbying Firm" by Ben Protess on December 29th, 2011). In addition the idea of an American media to be controlled by a Chinese firm was expected to face obstacles in Washington. This example is particular given the prominent role of the Chinese government in his economy and the role of a large media company but still shows that foreign firms face difficulties to invest in the US and that their lobbying activity is particularly covered in the media.
} 
When the government accepts contributions from the lobbies, his objective is a weighted average of his social welfare $\mathrm{W}$ and the political contributions: ${ }^{11}$

$$
\mathbb{G}\left(M, M^{*}, c, c^{f}\right)=a W\left(M, M^{*}\right)+c+\gamma c^{f}
$$

with $\gamma$ is the government's valuation of foreign contributions with $\gamma \geq 0$.

This part ends the description of the economic and political structure of country Home. The two countries, Home $($ no $*$ ) and Foreign $(*)$, are symmetric. I now consider the games played by the two countries to decide their FDI policies.

\section{The non-cooperative game between the two governments}

In this section, countries simultaneously decide their FDI policy $(M)$ in a non-cooperative way. The policy is chosen through either a simple maximisation of the social welfare or a lobbying game. I describe here the outcome in country Home.

The timing There are two periods in this game. At the beginning, the number of domestic firms born in each country $\left(M_{n}\right)$ is fixed. At $t=1$ the government chooses the FDI policy, i.e the number of foreign affiliates that can enter the country, when playing the political game with the two lobbies or not. At $t=2$, given the total numbers of firms $(M)$, production and consumption happen. The same timing happens in the other country.

The equilibrium is solved by backward induction starting from the production/consumption equilibrium at $t=2$. There are no exports such that the price only depends on the number of firms that have entered the country. The solutions are those of an oligopolistic setting with $M$ firms. I now focus on the policy choice of the government at the period $t=1$.

\subsection{The non-cooperative game with no lobbying}

I first consider the non-cooperative game when there is no lobbying. There is no contributions and lobbies do not exert an influence on the government. The FDI policy is chosen by maximizing the social welfare $W$. In this non-cooperative game, the government does not consider the impact of its choice on the policy of the other country. Given the policy in the other country $M^{*}$, the number of firms that maximizes the social welfare $\mathrm{W}$ defined in equation 2.10

$$
M_{0}=\underset{M}{\operatorname{argmax}} W\left(M, M^{*}\right) \quad \text { st. } \quad M_{n} \leq M \leq 2 M_{n}
$$

The full expression of $M_{0}$ is given in the annex 8.4.1. First we can notice that the solution $M_{0}$ does not depend on the similar policy choice of the Foreign government $M^{*}$ because of the linearity of the profits. Second the solution is restricted because the total number of firms can not exceed the sum of existing firms from the two countries $\left(M_{n}+M_{n}^{*}=2 M_{n}\right){ }^{12}$

\footnotetext{
${ }^{11}$ Similarly to Grossman and Helpman (1994), I rewrite the initial weights $(A, B, D)$ to have the following expression. Initially the expression is given by $G=A W()+B c+D c^{f}$ and is then rewritten $G=a W()+c+\gamma c^{f}$ with $a=\frac{A}{B-A}$ and $\gamma=\frac{D-A}{B-A}$ with $B>A$.

${ }^{12}$ I previously assumed no firm entry.
} 
Lemma 1 In the non-cooperative game with no lobbying, FDI policies are increasing in the taste for variety (i.e decreasing in the substitution index $\delta$ ) such that

$$
\begin{array}{ll}
\text { if } \delta=1 \text { (homogenous goods }), & M_{0}=M_{0}^{*}=\min \left(2 M_{n}, \max \left(\frac{(A-\phi)-M_{n}(\phi-z)}{\left(1+M_{n}\right)(\phi-z)}, M_{n}\right)\right) \\
\text { if } \delta=0(\text { independent goods }) & , \quad M_{0}=M_{0}^{*}=2 M_{n}
\end{array}
$$

There exists a threshold $\delta_{0}$ such that FDI policies are always free-entry $\left(=2 M_{n}\right)$ when consumers sufficiently care for variety $\left(\delta \leq \delta_{0}\right)$.

Proof. Existence of $\delta_{0}$ comes from $\frac{\partial M_{0}}{\partial \delta}<0$.

Lemma 1 provides a necessary condition for restrictions to be chosen. Consumers that care a lot about variety have a low substitution index. For $\delta=0$, every firm is a monopolist in its own market and profits do not decrease in the number of firms any more. Governments then choose high entry which increases the consumer surplus and the foreign producers' surplus without decreasing the domestic producers' surplus. For $\delta=1$ profits decrease in the number of firms and the government takes into account the producers' loses.

For the rest of the paper I focus on homogenous goods $(\delta=1)$. Consumer have little taste for variety and competition between firms is high. This choice for an extreme value is done for simplicity in order to study the emergence of restrictions chosen by governments.

Lemma 2 In the non-cooperative game with no lobbying, FDI policies, i.e. the number of firms, are decreasing in the repatriation of profits $(\phi)$. There exists a threshold $\phi_{0}$ such that FDI policies are not restricted when repatriation is sufficiently low $\left(\phi \leq \phi_{0}\right)$.

Proof. Existence of $\phi_{0}$ comes from $\frac{\partial M_{0}}{\partial \phi}<0$. The solution is given by: $\phi_{0}=z+\frac{A+z\left(M_{n}+1\right)}{1+2 M_{n}\left(1+M_{n}\right)}$.

Repatriation of profits creates a first economic motive for foreign restrictions. Foreign affiliates enter the country, compete with domestic firms and therefore decrease domestic firms' individual profits. In addition foreign affiliates only redistribute a share of the profits from their Home sales. The revenue of the Home consumer can be decreasing in more entry if the additional revenues from foreign firms do not compensate the loses from the domestic firms. The rest of foreign affiliates' profits is repatriated and benefits the Foreign consumer. In the absence of repatriation of profits $(\phi=z)$, governments always choose free-entry to reduce the frictions from imperfect competition. Perfect competition is never reached because the number of affiliates is restricted by the number of foreign firms $\left(M_{n}\right)$ that can open an affiliate. In this paper, for simplicity, I assume that there is no cost of opening an affiliate. ${ }^{13}$ Such a cost could also be a rationale for governments to restrict the number of producers and reduce the inefficiency from the waste of resources due to entry costs. This is not the motive that is explored in this model where governments choose to restrict entry to balance the benefits from more entry which decreases prices and the revenue loses due to the repatriation of profits. Entry is not restricted if repatriation of profits is low enough. Finally it can be shown that entry decreases in the number of domestic firms $\left(M_{n}\right)$. A larger number of domestic firms $M_{n}$ increases the weight on individual

\footnotetext{
${ }^{13}$ This assumption does not affect the results of this paper given that all firms are the same. Further work should be done to relax this assumption and study heterogenous firms when a cost affects entry. It would also change the objective of the lobby.
} 
profits, which decrease in the number of foreign firms. The government values more individual profits and tend to decrease entry.

Definition 1 Internationally efficient FDI policies maximize the world welfare (the sum of the two countries' welfare): $\max _{\left(M, M^{*}\right)} W\left(M, M^{*}\right)+W^{*}\left(M^{*}, M\right)$ where $W$ is the welfare of country $H$ and $W^{*}$ the welfare of country $F$.

Proposition 1 The non-cooperative equilibrium with no lobbying is inefficient when profits are largely repatriated $\left(\phi \geq \phi_{0}\right)$.

Proof. The set of Pareto-improving outcomes is given by the interval $\left[M_{0}, 2 M_{n}\right]^{2}$.

In the non-cooperative game, governments do not internalize the impact of their policy on the utility of the other government. The Home government only considers foreign affiliates' profits that benefit the Home consumer. However the Home consumer also benefits from the repatriated profits of the foreign sales that are not taken into account by the government when choosing his policy. Higher entry in the Foreign country implies more Home firms opening an affiliate abroad and therefore more repatriated profits. Both consumers could then benefit from higher entries in the two countries. This leads the equilibrium to be inefficient. However, the number of additional foreign firms that enter the country is limited by the number of firms abroad $\left(M \leq 2 M_{n}\right)$. When the constraint is binding $\left(M_{0}=2 M_{n}\right)$, the equilibrium is efficient.

\subsection{The non-cooperative game with lobbying}

I now consider the non-cooperative game between the two governments when each government plays a political game. At $t=1$, the government and the two lobbies can bargain to determine the policy $M$. The lobbies give contributions to exert an influence on the government. In addition I assume that foreign and domestic contributions can be differently valued.

\subsubsection{The bargaining game}

Following Maggi and Rodriguez-Clare (1998) ${ }^{14}$ I model the political game as a bargaining game between the government and the lobbies. I choose a bargaining game rather than a menu-auction game and study the outcomes of equilibria where not all players choose to bargain. One lobby can choose not to participate in the bargaining game and let the government and the other lobby decide on the FDI policy. I could have considered different cases in which foreign firms are exogenously allowed or not to lobby the government. However, the presence of foreign lobbying is important in the paper and the endogenous formation of bargaining coalitions enriches the results.

Whereas it is easy to model a bargaining game between two players, a game with three players is more demanding. I then use the concept of "coalitional bargaining" developed in Compte and Jehiel (2010). This definition can be applied to bargaining games with any number of players and is conceptually close to the definition used for two players. The difference comes

\footnotetext{
${ }^{14}$ There are two possibilities to model this political game: the menu-auction game or the bargaining game. They are relatively close and differ only in the way to divide the joint surplus between the different players. In the menu-auction game, the government always gets his outside option, whereas in the bargaining game he gets a share of the joint surplus that depends on his bargaining power.
} 
from the possibility for any subset of players to deviate from the grand coalition and form a sub-coalition. In my paper, there are three possible outcomes: the grand coalition with the three players, the sub-coalition between the government and the domestic lobby called "the domestic sub-coalition" and the sub-coalition between the government and the foreign lobby called "the foreign sub-coalition". The two lobbies cannot coordinate not to participate in the bargaining game. The grand coalition solution maximizes the Nash product for the three players, and additional constraints on the final allocations verify that none of the subsets of two players wants to deviate. The equilibrium is the solution of the Nash product maximization given the constraints that no sub-coalition would get more by deviating. However a sub-coalition can form if the grand coalition equilibrium has no solution. I discuss these possibilities later.

Definition 2 (Bargaining in the grand coalition) Given the policy in the other country $M^{*}$, the policy and contributions that are solutions of the bargaining game between the government and the two lobbies maximize the following constrained Nash product:

$$
\begin{aligned}
\left(M^{G}, c^{G}, c^{f G}\right)= & \operatorname{argmax}\left[G\left(M, M^{*}, c, c^{f}\right)-G_{0}\right]^{\sigma_{G}}\left[L(M, c)-L_{0}\right]^{\sigma_{N}}\left[L^{f}\left(M, c^{f}\right)-L_{0}^{f}\right]^{\sigma_{F}} \\
\text { st. } \quad & G(.)+L(.) \geq \mathbb{J}^{\mathbb{D}} \quad \text { (binding domestic sub-coalition) } \\
& G(.)+L^{f}(.) \geq \mathbb{J}^{\mathbb{F}} \quad \text { (binding foreign sub-coalition) }
\end{aligned}
$$

with $G_{0}$ the outside option of the government, $L_{0}\left(L_{0}^{f}\right)$ the outside option of the domestic lobby (of the foreign lobby) and $\mathbb{J}^{\mathbb{D}}\left(\mathbb{J}^{\mathbb{F}}\right)$ the joint surplus of the two players in the domestic sub-coalition (in the foreign sub-coalition). $\sigma_{G}$ is the bargaining power of the government.

The following graphic shows the possible four different cases that can appear in this situation.

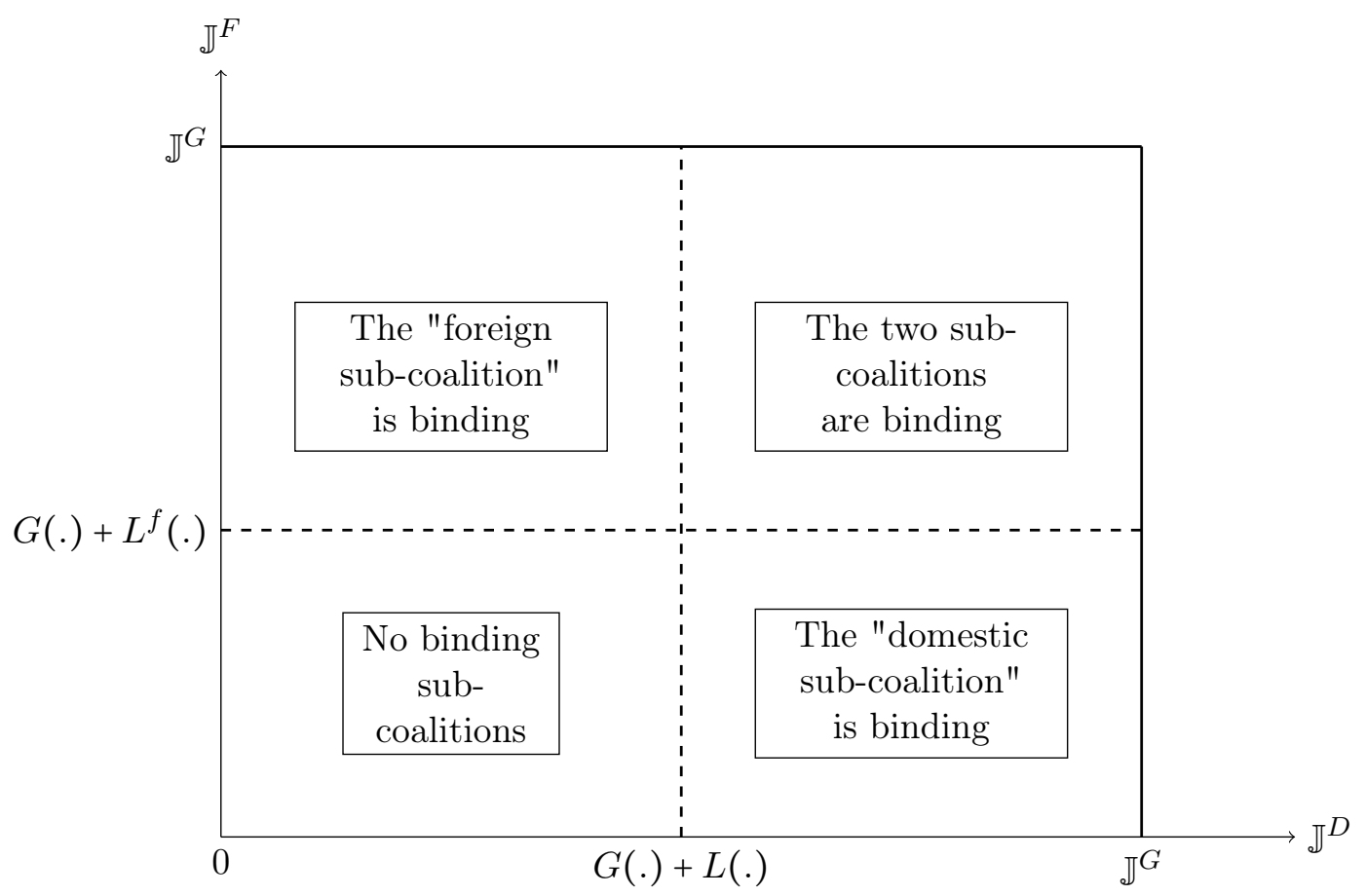

Figure 2: The four different cases depending on which constraint is binding. 
Lemma 3 In the grand coalition, the solution $M^{G}$ of the Nash product maximization defined by

$$
M^{G} \quad \text { st. } \quad a W^{\prime}\left(M^{G}\right)+\Pi^{\prime}\left(M^{G}\right)+\gamma \Pi^{* f^{\prime}}\left(M^{G}\right)=0 \quad \wedge \quad M_{n} \leq M^{G} \leq 2 M_{n}
$$

is efficient as it maximizes the joint surplus of the grand coalition $\mathbb{J}^{\mathbb{G}}$ defined by:

$$
\mathbb{J}^{\mathbb{G}}(M)=a W(M)+\Pi(M)+(\gamma-1) c^{f}+\Pi^{f}(M)
$$

Proof. The expression of the foreign contribution $\left(c^{f}\right)$ can be found from the allocation system defined by the bargaining powers of each agent or by the constraints when they are binding. The full proof is done in annex 8.4.1.

I then define the policies in the sub-coalitions in order to get the outside options and the joint surpluses of the sub-coalitions $\left(\mathbb{J}^{\mathbb{D}}\right.$ and $\left.\mathbb{J}^{\mathbb{F}}\right)$ that define the constraints.

Definition 3 (Bargaining in the domestic sub-coalition) Given the policy in the other country $M^{*}$, the policy and the contribution that are solutions of the bargaining game between the government and the domestic lobby maximize the following Nash product:

$$
\left(M^{D}, c^{D}\right)=\operatorname{argmax}\left[G\left(M, M^{*}, c\right)-M_{0}\right]^{\sigma_{G}}\left[L(M, c)-\tilde{L_{0}}\right]^{1-\sigma_{G}}
$$

with $M_{0}$ the outside option of the government, $\tilde{L}_{0}$ the outside option of the domestic lobby.

The solution in the domestic sub-coalition maximizes the joint surplus of the sub-coalition. The outside option of the lobby is the profit given the policy $M_{0} . M^{D}$ is the policy chosen in the domestic sub-coalition such that

$$
M^{D} \quad \text { st. } \quad a W^{\prime}\left(M^{D}, M^{*}\right)+\Pi^{\prime}\left(M^{D}\right)=0 \quad \wedge \quad M_{n} \leq M^{D} \leq 2 M_{n}
$$

Definition 4 (Bargaining in the foreign sub-coalition) Given the policy in the other country $\left(M^{*}\right)$, the policy and the contribution that are solutions of the bargaining game between the government and the foreign lobby maximize the following Nash product:

$$
\left(M^{F}, c^{f F}\right)=\operatorname{argmax}\left[G\left(M, M^{*}, c^{f}\right)-M_{0}\right]^{\sigma_{G}}\left[L^{f}\left(M, c^{f}\right)-\tilde{L_{0}^{f}}\right]^{1-\sigma_{G}}
$$

with $M_{0}$ the outside option of the government and $\tilde{L_{0}^{f}}$ the outside option of the foreign lobby in the sub-coalition game.

Similarly the solution in the foreign sub-coalition maximizes the joint surplus of the sub-coalition with the foreign lobby. The outside option of the lobby is the profit given the policy $M_{0} . M^{F}$ is the policy chosen in the foreign sub-coalition such that

$$
M^{F} \quad \text { st. } \quad a W^{\prime}\left(M^{F}, M^{*}\right)+\gamma \Pi^{* f^{\prime}}\left(M^{F}\right)=0 \quad \wedge \quad M_{n} \leq M^{F} \leq 2 M_{n}
$$

The bargaining game is defined by the FDI policy $M^{G}$ and the allocations $\left(G(),. L(),. L^{f}().\right)$ for the three players that depend on the contributions $\left(c^{G}, c^{f G}\right)$. These allocations are defined 
either through the maximization of the Nash product according to each player's bargaining power or through the binding constraints. The final allocations depend both on the bargaining powers of the government and the two lobbies, and on the outside options of each player.

The outside option of the government is given by the FDI policy $M_{0}$ defined previously. The outside option of the domestic lobby is given by the utility obtained when it does not participate to the lobbying game. Its outside option is $L_{0}=M_{n} \pi\left(M^{F}\right)$ with $M^{F}$ the policy chosen in the foreign sub-coalition from Definition 4. The outside option of the foreign lobby is similarly defined by $\left.L_{0}^{f}=\left(M^{D}-M_{n}\right) \pi^{* f}\left(M^{D}\right)\right)$ with $M_{N}$ the policy chosen by the domestic sub-coalition.

For the rest of the paper I want to focus on the interesting case when foreign lobbying pushes for more entry and counteracts domestic lobbying.

Lemma 4 There exists a threshold $\tilde{M}_{n}$ such that $\left.\frac{\partial M^{G}}{\partial \gamma}\right|_{\tilde{M}_{n}}=0$ and

$$
M_{n} \leq \tilde{M}_{n} \Rightarrow \frac{\partial M^{G}}{\partial \gamma} \leq 0 \quad \wedge \quad M_{n} \geq \tilde{M}_{n} \Rightarrow \frac{\partial M^{G}}{\partial \gamma} \geq 0
$$

For the rest of the paper I restrict the set of numbers of domestic firms such that $M_{n} \geq \tilde{M}_{n}$.

The number of domestic firms $M_{n}$ determines the objective of the foreign lobby and its impact on the policy. When there are few domestic firms, the FDI policy chosen by the government is relatively large and the individual profits relatively small. The lobby of foreign firms then pushes for more restrictions to increase individual profits at the cost of reducing the number of affiliates that enter. When there are many domestic firms, the restrictions and the individual profits are higher. The lobby of foreign firms pushes for more entry at the cost of reducing the individual profits of each affiliate. In the first case, foreign lobbying exerts an influence for higher restrictions. A deeper analysis of the objective of the lobby of foreign firms is provided in another work Fiorini and Lebrand (2016). In the rest of the paper, I restrict my analysis to the case of a number of domestic firms large enough so that a higher valuation of foreign contributions leads to more entry.

Lemma 5 Compared to the policy in the grand coalition, entry is lower in the domestic subcoalition $\left(M^{D} \leq M^{G}\right)$ and higher in the foreign sub-coalition $\left(M^{G} \leq M^{F}\right)$.

Such ranking directly results from Lemma 4. Domestic lobbying pushes towards lower entry whereas foreign lobbying pushes towards higher entry. In the grand coalition the two lobbies bargain and the solution is a compromise between domestic and foreign interests.

\subsubsection{Equilibrium when contributions are equally valued $(\gamma=1)$}

I present here the outcome of the non-cooperative equilibrium between the two governments when each government can play a bargaining game with his lobbies. I assume first that foreign and domestic contributions are equally valued $(\gamma=1)$ then I relax this assumption in the next part. For simplicity I also assume that the government's bargaining power is null $\left(\sigma_{G}=0\right)^{15}$.

\footnotetext{
${ }^{15}$ This assumption is not restrictive. In this paper I do not discuss whether governments prefer either playing the political game to receive contributions or committing in an agreement. Maggi and Rodriguez-Clare (1998) show that there exists a threshold that can explain why some governments sign agreements or not.
} 
Definition 5 The non-cooperation political equilibrium is defined by a pair of FDI policies $\left(M^{G}\right.$, $\left.M^{* G}\right)$, domestic and foreign contributions for the Home government $\left(c^{G}, c^{f G}\right)$ and for the Foreign government $\left(c^{\star G}, c^{\star f G}\right)$ that are solutions of the bargaining games in each country, and by prices and quantities defined previously in the Cournot equilibrium.

Proposition 2 The equilibrium when contributions are equally valued $(\gamma=1)$ has a solution with the grand-coalition bargaining. The FDI policies are given by:

$$
M^{G}=M^{* G}=\min \left(2 M_{n}, \max \left(\frac{(a+1)\left[(A-\phi)+M_{n}(z-\phi)\right]}{(A-z)+\left(1+M_{n}\right)(a+1)(\phi-z)}, M_{n}\right)\right)
$$

The Home government's allocation is given by: $G\left(M^{G}, M^{* G}, c^{G}, c^{f G}\right)$

$$
= \begin{cases}a W\left(M_{0}, M_{0}^{*}\right) \wedge c^{G}, c^{f G} \geq 0 & \text { if at most one sub-coalition is binding and } M^{G}<M_{0} \\ a W\left(M^{G}, M^{* G}\right) \wedge c^{G}, c^{f G}=0 & \text { if at most one sub-coalition is binding and } M^{G} \geq M_{0} \\ \mathbb{J}^{\mathbb{D}}+\mathbb{J}^{\mathbb{F}}-\mathbb{J}^{\mathbb{G}} & \text { if the two sub-coalitions are binding. }\end{cases}
$$

The Foreign government's allocation is symmetric.

Proof. The grand coalition is always the solution for $\gamma=1$. A sub-coalition can not lead to a higher total surplus: $\mathbb{I}^{\mathbb{D}}\left(M^{D}, M^{*}\right)+\Pi^{* f}\left(M^{D}\right)<\mathbb{J}^{\mathbb{D}}\left(M^{G}, M^{*}\right)+\Pi^{* f}\left(M^{G}\right)$ and $\mathbb{J}^{\mathbb{F}}\left(M^{F}, M^{*}\right)+$ $\Pi^{\star f}\left(M^{F}\right)<\mathbb{J}^{\mathbb{F}}\left(M^{G}, M^{*}\right)+\Pi\left(M^{G}\right)$. More details in Appendix 8.4.1.

The grand coalition with the three players is the equilibrium coalition when both domestic and foreign contributions are equally valued $(\gamma=1)$. In the previous part that defines the equilibrium without lobbying, FDI restrictions are chosen only because of the repatriation of profits by foreign affiliates. I add a political motive to the economic rationale and consider political forces that can exert an influence on governments. The absence of repatriation of profits is not sufficient to have free-entry any more. The effect of lobbying depends on the foreign lobby that can strive for two opposite objectives: more entry or higher restrictions to increase individual profits.

In such bargaining models, the government at least gets his outside option $\left(a W\left(M_{0},.\right)\right)$ and gets no more than his outside option when his bargaining power is null. The difference in this paper is explained by the presence of the policy chosen by the Foreign government in the utility function of the Home government. The Home government considers $M_{0}$ as his outside option in the bargaining game. The difference comes from the final allocation of the government here. Even if the government has no bargaining power, the equilibrium outcome for the government in Proposition 2 can differ from the outcome defined by the outside policy option $M_{0}\left(=a W\left(M_{0},.\right)\right)$. The reason is that each government chooses his policy without considering the policy of the other government. What is the best outside policy for the government might not be the best policy if the government has considered that the other government would choose the same policy. The outside outcome $\left(a W\left(M_{0}, M_{0}^{*}\right)\right)$ is the equilibrium outcome of the government only when the policy outcome delivered in the grand coalition bargaining is lower than the policy that defines his outside option $\left(M^{G} \leq M_{0}\right)$. In that case the outside outcome is higher than the one obtained by the equilibrium policy choice $\left(a W\left(M_{0}, M_{0}^{*}\right)>\left(a W\left(M^{G}, M^{G *}\right)\right)\right.$. The interesting part of the proposition arises when the policy solution is higher than the policy chosen $M^{G} \geq M_{0}$. As 
assumed previously, the government has a null bargaining power $\left(\sigma_{G}=0\right)$ and both countries are symmetric. In the first case $M^{G} \leq M_{0}$, lobbying leads to more restrictions than what the government would optimally choose in case of no lobbying. His outside option $\left(a W\left(M_{0}, M_{0}^{*}\right)\right)$ is larger than his objective function with the new policy $M^{G}\left(a W\left(M_{0}, M_{0}^{*}\right)>\left(a W\left(M^{G}, M^{G \star}\right)\right)\right.$ and the government receives positive contributions from at least one lobby. However the entry policy from the bargaining game can be larger (less restrictive) than in the case of no lobbying $\left(M^{G} \geq M_{0}\right)$. The utility of the government after bargaining even without bargaining power is then higher than in his outside option $\left(a W\left(M^{G}, M^{* G}\right)>a W\left(M_{0}, M_{0}^{*}\right)\right)$. The government does not need to be compensated for playing the political game any more. This result contrasts with Maggi and Rodriguez-Clare (1998) in which the government always needs to be compensated. This will allow us to draw interesting results on the gains from having foreign lobbying that can allow the government to reach a better outcome from a social welfare point of view.

Lemma 6 A higher level of repatriation of profits results in lower entry, i.e. higher restrictions, in the two countries.

Proof. I show that $\frac{\partial M^{G}}{\partial \phi} \geq 0^{16}$.

The economic motive for restrictions still applies when political forces affect the choice of the government. The presence of profit repatriation is necessary to have an outside option different from free-entry $\left(M^{G}<2 M_{n}\right)$. Similarly to the previous part, a higher repatriation of profits provides incentives for the governments to restrict foreign entry. I now compare the FDI policies in the game without lobbying $M_{0}$ and the game with lobbying $M^{G}$. The outcome depends on the extent to which foreign lobbying counteracts domestic lobbying.

Proposition 3 There exist a 'Lobby threshold' $\phi_{L}$ such that entry in the lobbying game is higher than entry in the no-lobbying game $\left(M^{G} \geq M_{0}\right)$ when the repatriation of profits is limited $\phi<\phi_{L}$. Lobbying is then welfare-improving compared to the outcome with no lobbying.

Proof. $\phi_{L}$ is defined by $\left.M^{G}\right|_{\phi_{L}}=M_{0}$ given that $\left.M^{G}\right|_{\phi=P\left(M^{G}\right)}<M_{0}$ and $\left.M^{G}\right|_{\phi=z}>M_{0}$. When all profits are repatriated, foreign lobbying does not have an influence on the government.

Proposition 3 defines the levels of repatriation for which foreign lobbying leads to higher entry than the outcome of the non-political game. According to Proposition 2, governments' allocations are given by their outside options and contributions are positive when foreign entry is lower than in the game without lobbying $\left(M^{G}<M_{0}\right)$. On the contrary, the government gets more than his outside option if entry is higher $\left(M^{G} \geq M_{0}\right)$. A higher entry is also chosen in the other symmetric country. The Home consumer then benefits from the higher number of Home parents that repatriate part of their profits from sales in the Foreign country. This is the source of the inefficiency described in Proposition 1. The government can then be strictly better-off by playing the lobbying game. Foreign lobbying helps the government to internalize the inefficiency of proposition 1. The welfare increases when foreign lobbying helps the government to choose a higher entry level than $M_{0}$. This happens when the level of repatriation is low enough.

\footnotetext{
${ }^{16}$ When the solution is binding $\left(M^{G}=M_{n}\right.$ or $\left.M^{G}=2 M_{n}\right)$, a higher level of repatriation of profits does not affect the FDI policy.
} 


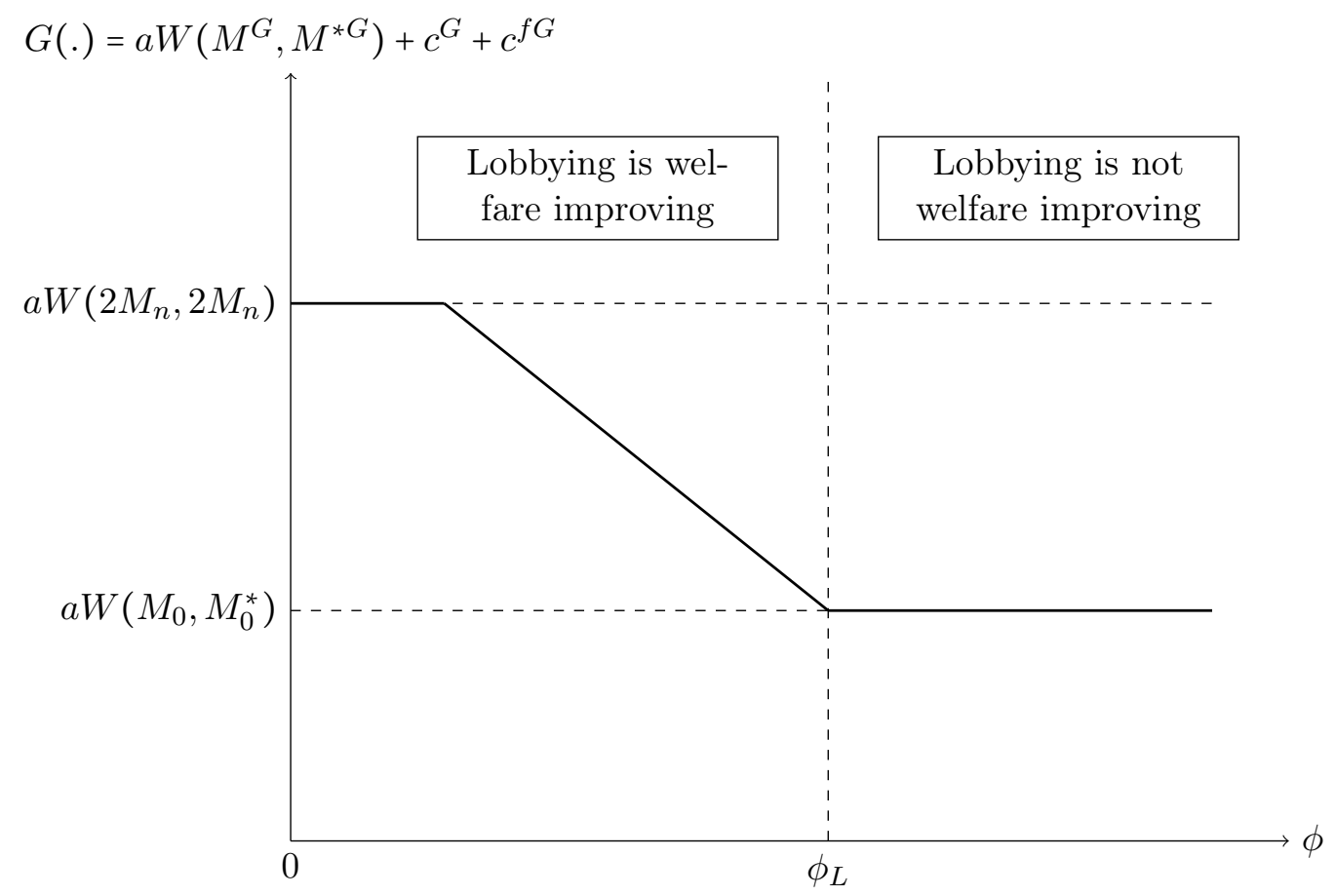

Figure 3: The government's allocation for different repatriation of profits $\phi$.

\subsubsection{Equilibrium when contributions are differently valued $(\gamma \neq 1)$}

I now consider that governments differently value foreign and domestic contributions. I discuss whether bargaining in the grand coalition always has a solution. Different valuations directly affect the impact of foreign lobbying in helping governments to decrease their FDI restrictions. Similarly to Gawande et al. (2006) I study the case of foreign contributions being differently valued than domestic contributions. In their paper all lobbies participate in the political game. I extend the model by assuming a bargaining game which brings more possibilities. Bargaining subcoalitions can be formed in which not all firms participate in the political game. The definition of "coalitional bargaining" from Compte and Jehiel (2010) allows for the formation of subcoalitions if there is no solution in the grand coalition bargaining equilibrium. However a cost of redistributing the surplus between the players, which is not considered in the paper, emerge when foreign and domestic contributions are not equally valued $(\gamma=1)$. I provide the conditions for sub-coalitions to emerge.

Lemma 7 For $\gamma \neq 1$, subcoalitions can form when there is no solution in the grand coalition equilibrium. This happens when the joint surplus for all the players is larger for at least one sub-coalition than in the grand coalition.

$$
\begin{aligned}
& \left\{M^{G}, c^{G}, c^{f, G}\right\}=\varnothing \quad \Leftrightarrow \\
& \quad \mathbb{J}^{\mathbb{D}}\left(M^{D}, M^{*}\right)+\Pi^{* f}\left(M^{D}\right)>\mathbb{J}^{G}\left(M^{G}, M^{*}\right) \quad \vee \quad \mathbb{J}^{F}\left(M^{F}, M^{*}\right)+\Pi\left(M^{F}\right)>\mathbb{J}^{G}\left(M^{G}, M^{*}\right)
\end{aligned}
$$

Proof. I first show that the total surpluses from the sub-coalitions can be larger than the total surplus in the grand coalition, which was never possible for $\gamma=1$. The amount of optimal 
foreign contributions affects the size of the surplus and the total surplus functions can differ form the surplus in the grand coalition ${ }^{17}$ :

$$
\gamma \neq 1 \Rightarrow \begin{cases}\mathbb{J}^{N}\left(M, M^{*}\right)+\Pi^{* f}(M) \neq \mathbb{J}^{G}\left(M, M^{*}\right) & \text { if the domestic sub-coalition bargains, } \\ \mathbb{J}^{F}\left(M, M^{*}\right)+\Pi\left(M^{F}\right) \neq \mathbb{J}^{G}\left(M, M^{*}\right) & \text { if the foreign sub-coalition bargains }\end{cases}
$$

Contrary to Proposition 2, it is now possible to have a larger total surplus when a sub-coalition is bargaining than when the grand coalition bargains. Second I show that the grand coalition equilibrium does not have a solution if the total surplus for the three players from either the domestic sub-coalition or the foreign sub-coalition is larger than the total surplus of the grand coalition. The proof comes from the constraints in the grand coalition bargaining. I denote by $G(), L(), L^{*}()$ the allocations for the government and the two lobbies in the grand coalition. Let's take the case of a surplus strictly higher with the domestic sub-coalition. If a solution exists in the grand coalition, it should respect the following constraints: $G()+L() \geq \mathbb{J}^{\mathbb{D}}\left(M^{D}, M^{*}\right)$ and $L^{*}() \geq \Pi^{* f}\left(M^{D}\right)$. This leads to a contradiction because $G()+L()+L^{*}()=\mathbb{J}^{G}\left(M^{G}, M^{*}\right) \geq$ $\mathbb{J}^{\mathbb{D}}\left(M^{D}, M^{*}\right)+\Pi^{* f}\left(M^{D}\right)$ and by assumption $\mathbb{J}^{G}\left(M^{G}, M^{*}\right)<\mathbb{J}^{\mathbb{D}}\left(M^{D}, M^{*}\right)+\Pi^{* f}\left(M^{D}\right)$.

Equilibria with sub-coalitions can emerge given that the surplus for all three players can be larger in a sub-coalition formation than in the grand coalition. This implies that there is not enough surplus generated in the grand coalition to find allocations that verify the contraints. A unit of contribution from the foreign lobby is redistributed to the government and the size of the surplus does not vary with the amount of contributions. This only happens when contributions are differently value $(\gamma \neq 1)$. When governments differently value domestic and foreign contributions, the way to share the surplus affects its total size. When $\gamma<1$, the surplus that is shared between the three players is decreasing in foreign contributions. Only a percentage $\gamma$ of what is given by the foreign lobby benefits the government. Therefore there is a loss of surplus due to this difference in valuation.

Proposition 4 (Sub-coalitions) When foreign contributions are undervalued $(\gamma<1)$, we can show that

- for any level of government's valuation of foreign contributions, there exists a threshold for the repatriation of profits $\phi^{s u b} \in \Phi^{18}$ above which bargaining in the grand coalition has a solution and below which a sub-coalition is formed.

$$
\forall \gamma \in(0,1), \quad \exists \phi^{s u b} \in \Phi \quad \text { st. } \quad \begin{cases}\phi \leq \phi^{\text {sub }} & \Rightarrow\left(M, M^{*}\right)=\left(M^{G}, M^{* G}\right) \\ \phi \geq \phi^{\text {sub }} & \Rightarrow\left(M, M^{*}\right)=\left(M^{D}, M^{* D}\right) \vee\left(M^{F}, M^{* F}\right)\end{cases}
$$

- for any level of repatriation, there exists a threshold for the valuation of foreign contributions $\gamma^{\text {sub }} \in[0,1]$ above which bargaining in the grand coalition has a solution and below which a

\footnotetext{
${ }^{17}$ All surplus functions were the same for $\gamma \neq 1$. The grand coalition that maximizes this joint surplus always maximizes the joint surplus for the three players.

${ }^{18}$ The interval $\Phi=\left[z, p\left(2 M_{n}\right)\right]$ defines all the possible values for repatriation. We choose the price with the maximum of firms $p\left(2 M_{n}\right)$ as an upper limit for the level of repatriation $\left(\forall M, p(M) \geq p\left(2 M_{n}\right)\right)$
} 
sub-coalition is formed.

$$
\forall \phi \in \Phi, \quad \exists \gamma^{s u b} \in[0,1] \text { st. } \begin{cases}\gamma \geq \gamma^{\text {sub }} & \Rightarrow\left(M, M^{*}\right)=\left(M^{G}, M^{* G}\right) \\ \gamma \leq \gamma^{\text {sub }} & \Rightarrow\left(M, M^{*}\right)=\left(M^{D}, M^{* D}\right) \vee\left(M^{F}, M^{* F}\right)\end{cases}
$$

\section{Proof. Annex 8.4.1.}

Proposition 4 shows that the grand coalition bargaining is more likely to have a solution when the repatriation of profits is low and the government's valuation is high. When the repatriation is low, the formation of a sub-coalition with the foreign firms only can lead to a better outcome than in the grand coalition. The joint surplus of the government and the foreign lobby can be higher especially when it is costly to transfer money from the foreign lobby towards the government $(\gamma<1)$. When the government's valuation is low, it becomes very costly to bargain in the grand coalition given that foreign contributions decrease the size of the joint surplus. It is therefore more efficient to bargain either only with the domestic or the foreign firms.

Figure 3.2.3 provides numerical simulations for the FDI policies (the left column) and for the total surpluses of the agents (the right column). Each graphic on the left shows the number of firms when either the grand coalition or one of the two sub-coalitions bargain and each graphic on the right shows the total surplus for all agents when either the grand coalition or one of the two sub-coalitions bargain. They show how these two variables vary with the government's valuation of foreign contributions for three levels of profits' repatriation. Each line shows FDI policies and joint surpluses for a different level of repatriation (low $\phi$ for the first line and higher $\phi$ for the second and third lines). The left column shows that the policies bargained in the two subcoalitions are mostly binding $\left(M^{D}=M_{n}\right.$ and $\left.M^{F}=2 M_{n}\right)$ whereas the policy bargained in the grand coalition increases in the government's valuation of foreign contributions. A higher weight on foreign profits leads to a higher entry of foreign firms. On the right, the figures show which surplus is the highest depending on which coalitions bargain. When the level of repatriation is very low (first line), the grand coalition game has a solution only when the government's valuation of foreign contributions is very close to one. The foreign subcoalition generates the highest joint surplus for the rest of the cases which implies that the government will bargain with the foreign lobby only and chooses the FDI policy $M^{F}$ defined in Definition 4 . The domestic sub-coalition never emerges when the repatriation is very low. The second line shows the same simulation for a higher value of profits' repatriation. The results are similar but the grand coalition has a solution for smaller values of government's valuation of foreign contributions. When the repatriation of profits increases the surplus generated when bargaining with foreign firms only becomes smaller and smaller compared to the surplus in the grand coalition. In the third case of an even higher repatriation, bargaining with domestic firms and increasing barriers to foreign entry leads to higher joint surplus than in the case of a bargaining with foreign firms only. Indeed more repatriation reduces the profits that are redistributed to Home consumers such that governments should care less and less about their interests and choose a policy that benefits domestic firms more.

In this section, I have shown the existence of an inefficiency in the non-cooperative game 

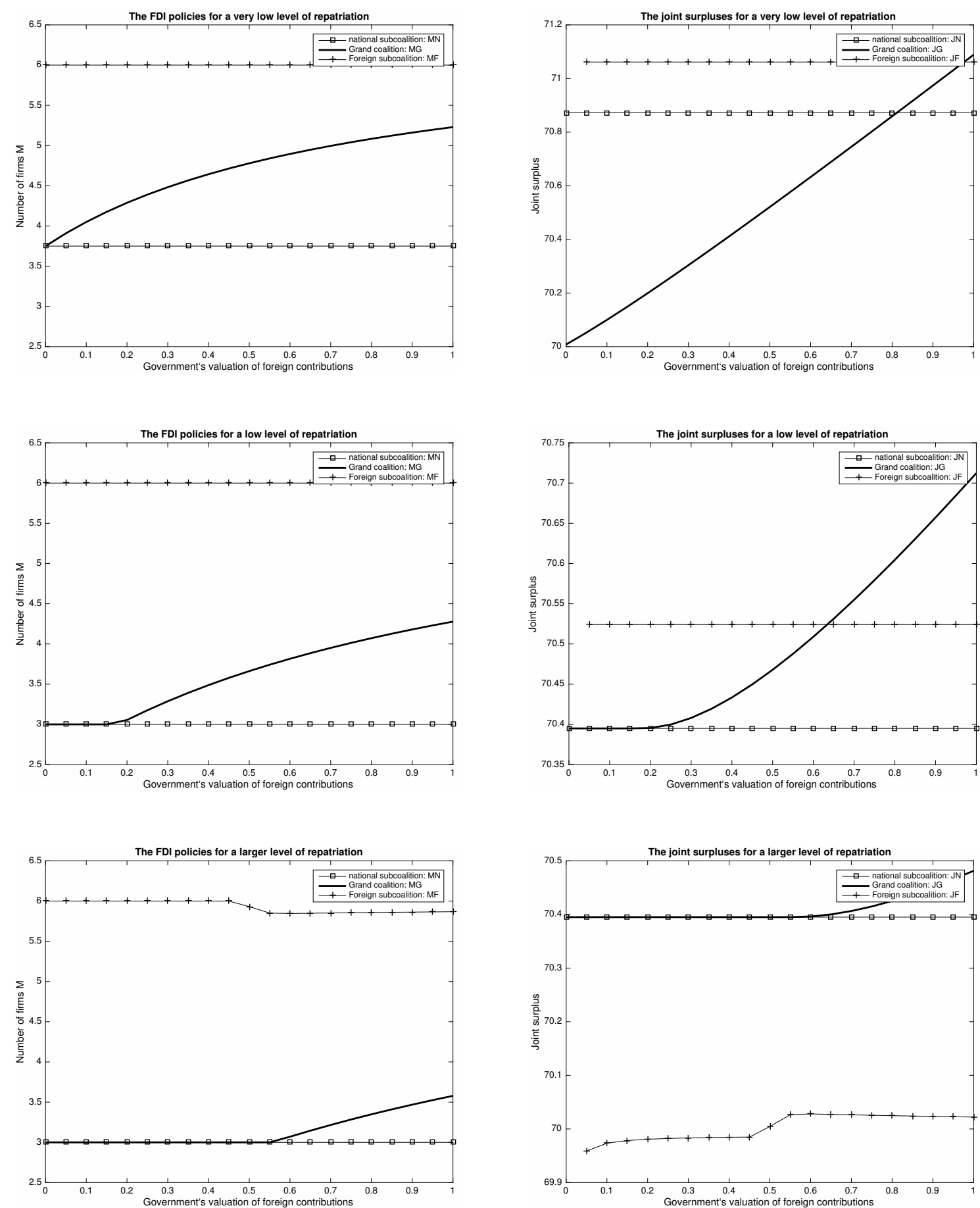

Figure 4: Effect of undervaluation of foreign contributions $(\gamma<1)$ on FDI policies chosen in a bargaining game $\left\{M^{D}, M^{\gamma}, M^{F}\right\}$ and joint surpluses $\left\{J^{N}+\Pi^{* f}, J^{\gamma}, J^{F}+\Pi\right\}$ for different levels of repatriation. 
given that foreign firms repatriate part of their profits in their country of origin. This leads the government to restrict entry. Depending on the degree of repatriation and of governments' valuation of foreign contributions, foreign lobbying can push for higher entry and help the government to internalize the inefficiency.

\section{Foreign lobbying and FDI agreements}

The presence of repatriation of profits by multinationals is a source of inefficiency when governments non-cooperatively choose their policies. Following Grossman and Helpman (1994), an agreement can solve for the inefficiency and help governments to internalize the externality. I first study the equilibrium when governments cooperatively choose their policy. However foreign lobbying also helps countries to indirectly internalize the externality. Could foreign lobbying then make an agreement unnecessary?

\subsection{The cooperative game between the two governments}

Following Grossman and Helpman (1995) and Maggi and Rodriguez-Clare (2007) I assume that the two symmetric countries play a bargaining game to choose the terms of the agreement ${ }^{19}$. There is no lobbying at the time when countries negotiate for an agreement.

Definition 6 An agreement is defined by the outcome of the cooperative game without lobbying.

The terms of the agreement are defined by

$$
\left(M^{a g}, M^{* a g}\right)=\arg \max _{M, M^{*}} W\left(M, M^{*}\right)+W^{*}\left(M^{*}, M\right) \wedge \quad\left(M^{a g}, M^{* a g}\right) \in\left[M_{n}, 2 M_{n}\right]^{2}
$$

and consist of $M^{a g}=M^{* a g}=2 M_{n}$.

The externality problem is internalized by governments in the cooperative game such that an agreement helps governments to choose efficient policies. The repatriated profits of the Home affiliates - given by $\left(M^{*}-M_{n}\right)\left[(\phi-z) q^{*}\left(M^{*}\right)\right]$ - are now taken into account by the Foreign government when choosing $M^{*}$, and vice versa.

\subsection{Foreign lobbying and FDI agreements}

Contrary to Grossman and Helpman (1994) and Maggi and Rodriguez-Clare (1998), the paper does not argue that agreements are not observed because governments prefer playing a domestic political game. Lobbying leads to higher trade barriers in a world where free trade is the optimal solution but is chosen because of the positive political contributions. The same reasoning could be applied here but I ruled out such conclusions by assuming $\sigma_{G}=0$ for the whole paper. ${ }^{20} \mathrm{I}$ here discuss whether agreements are not observed because lobbying can also help governments

\footnotetext{
${ }^{19}$ I follow Grossman and Helpman (1995) to model bargaining between the two governments using their result that having a transfer payment between the two governments or not gives the same results. I assume here that there is no transfer payments.

${ }^{20} \mathrm{I}$ then do not discuss conditions for which lobbying or an agreement is chosen. Under the assumption of no bargaining power $\left(\sigma_{G}=0\right)$, an agreement is preferred to the lobbying game. Following Maggi and Rodriguez-Clare (1998), I can show that there exists a threshold for the bargaining power such that a government with a high bargaining power does not sign an agreement.
} 
to reduce their FDI barriers. I consider foreign and domestic contributions first to be equally valued and second to be differently valued.

\subsubsection{Foreign contributions are equally valued $(\gamma=1)$}

I now discuss whether foreign lobbying can lead to the efficient policies that define the outcome of the agreement when foreign and domestic contributions are equally valued $(\gamma=1)$. I focus on the impact of the level of repatriation on the equilibrium.

Proposition 5 There exists a threshold $\widetilde{\phi^{a g}}$ such that the non-cooperative entry policies are equal to the terms of the agreement $\left(M^{G}=M^{a g}\right.$ and $\left.M^{* G}=M^{\star a g}\right)$ when the repatriation of profits is sufficiently low $\left(\phi \leq \widetilde{\phi^{a g}}\right)$.

Proof. $\widetilde{\phi^{a g}}$ is defined such that $\left.M^{G}\right|_{\widetilde{\phi^{a g}}}=M^{a g}=2 M_{n}$. Existence given by $\left.M^{G}\right|_{\phi=z}=2 M_{n}$.

A limited repatriation of profits allows foreign lobbying to push towards high entry. The policy chosen in the lobbying game can be equal to the terms of the agreement if the foreign affiliates redistribute enough to the domestic consumer such that the governments value their profits. An agreement can be unnecessary to help governments to internalize the externality and foreign lobbying is another channel for governments to choose not to restrict foreign entry. If foreign firms repatriate a lot of their profits, foreign lobbying can not push the government to choose the cooperative outcome. An agreement is therefore needed to fully internalize the inefficiency. This proposition suggests that the economic parameter $\phi$ can define the situations in which an agreement is necessary compared to the outcome of foreign lobbying.

\subsubsection{Foreign contributions are differently valued $(\gamma \neq 1)$}

I now discuss whether foreign lobbying can lead to the optimal entry policies when foreign and domestic contributions are differently valued $(\gamma \neq 1)$. I focus on results that depend on the government's valuation of foreign contributions.

Proposition 6 There exists a threshold $\widetilde{\gamma^{a g}}$ defined by $\left.M^{G}\right|_{\widetilde{\gamma^{a g}}}=M^{a g}$ for which the noncooperative entry policies are equal to the terms of the agreement if governments sufficiently value foreign contributions $\left(\gamma \geq \widetilde{\gamma^{a g}}\right.$ ) and if the grand coalition equilibrium has a solution (cf Proposition 4). Otherwise there exists a threshold $\widetilde{\gamma^{F, a g}}$ defined by $\left.M^{F}\right|_{\gamma^{F, a g}}=M^{a g}$ if the foreign sub-coalition is the solution (cf Proposition 4). In the case of the domestic sub-coalition, entry policies are never equal to the terms of the agreement.

A high government's valuation of foreign contributions allows foreign lobbying to exert a large influence on the government towards high entry. The policy chosen in the lobbying game can be equal to the terms of the agreement if foreign contributions are sufficiently valued. An agreement is therefore not necessary to help governments to internalize the externality. If foreign contributions are not highly valued, foreign lobbying can not push the government to choose the cooperative outcome. An agreement is therefore needed to fully internalize the inefficiency. This proposition suggests that the political parameter $\gamma$ can define a set of countries for which an agreement is not necessary to internalize the externality. Countries where foreign firms have no 
influence should rather sign an agreement to lower their restrictions. Foreign lobbying might be a good substitute to an agreement in countries where foreign influence is sufficiently valued. ${ }^{21}$

The following proposition compares the outcomes for the different sub-coalitions.

Result 1 When foreign and domestic contributions are differently valued $(\gamma \neq 1)$, I show that

i) the set of government's valuations of foreign contributions $\gamma$ for which the non-cooperative entry is equal than the terms of an agreement is larger in the foreign sub-coalition equilibrium than in the grand coalition equilibrium $\left(\left[\widetilde{\gamma^{a g}},+\infty\right) \subset\left[\widetilde{\gamma}^{F, a g}+\infty\right)\right)$,

ii) the set of share of profits that is repatriated in the country of origin $\phi$ for which the noncooperative entry is equal than the terms of an agreement is larger in the foreign sub-coalition equilibrium than in the grand coalition equilibrium $\left(\left[z, \widetilde{\phi}^{a g}\right] \subset\left[z, \widetilde{\phi}^{F, a g}\right]\right)$,

iii) the non-cooperative entry in the domestic sub-coalition is always lower than the terms of the agreement.

Proof. More details in Appendix 8.4.2.

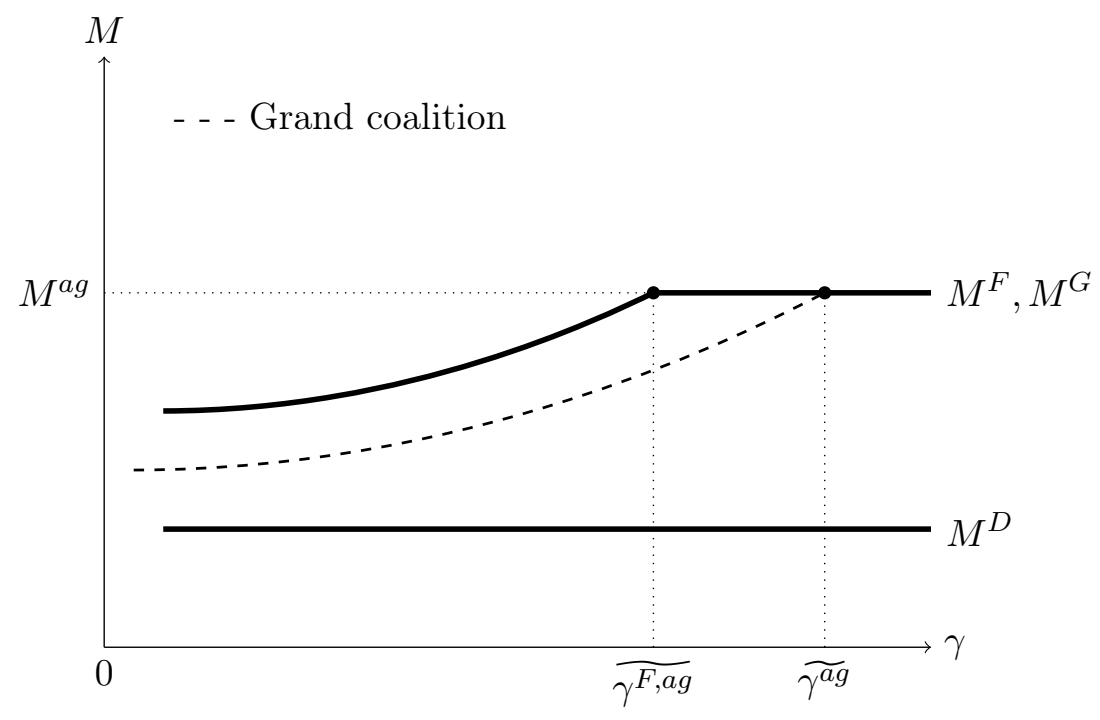

Figure 5: The thresholds for which the non-cooperative outcome with lobbying is equivalent to the agreement outcome for a given $\phi$.

Figures 5 and 6 illustrate Result 1. Result 1 implies that the outcome in the foreign subcoalition is more likely to be Pareto-efficient given that it requires a government's valuation of foreign contributions that is lower than in the case of the grand coalition. Finally bargaining in the domestic sub-coalition leads to restrictive policies which are never equal to the agreement policy.

\footnotetext{
${ }^{21}$ This is a result that I do not test in the paper but could lead to further empirical work.
} 


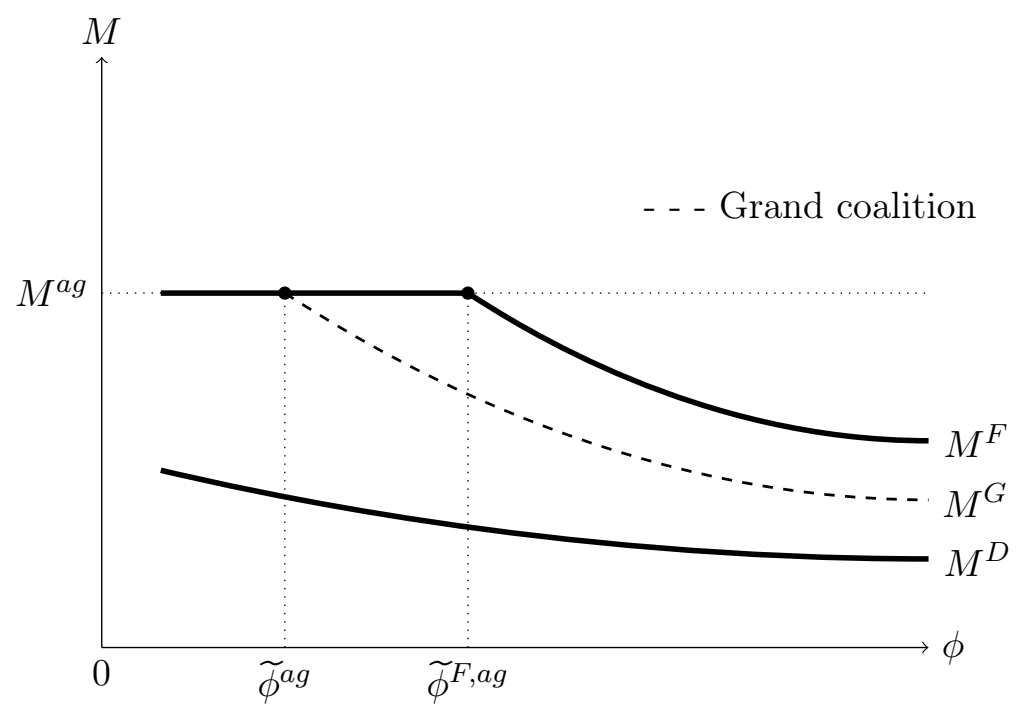

Figure 6: The thresholds for which the non-cooperative outcome with lobbying is equivalent to the agreement outcome for a given $\gamma$.

\section{Tax havens and FDI agreements}

In this part I consider the opportunity for multinationals to use transfer pricing to shift profits towards tax havens. All firms can shift profits in order to decrease the share of profits that is taxed in the country of origin and in the host country. This possibility affects the choice of FDI policies as well as the role of FDI agreements.

\subsection{Transfer pricing towards tax havens}

I now assume that all firms can locate the parents' profits in a tax haven. A tax haven is defined here as a place where corporate taxes are null and where firms can easily shift profits to. A tax haven has no consumer and profits that are shifted there are assumed not to benefit any country. This assumption can be discussed given that profits in tax havens have been shown to be partly reinvested and to indirectly benefit consumers from the country of origin. For simplicity I assume that these profits are not redistributed to consumers in the short-term. Firms can legally shift profits towards a tax haven if they locate the parents of the firms there. The parents can then provide intangible inputs to the affiliates in the host country where consumers are. These inputs are usually services or intangible goods paid at a price chosen by the firms. This intra-firm price determines the share of profits that is located in the two countries which then determines the FDI policies. Several papers (Davies et al. (2014), Vicard (2015)) have provided empirical proofs of the use of transfer pricing by multinationals to shift profits toward tax havens. Davies et al. (2014) especially finds out that profit shifting through transfer pricing mainly happens towards a few tax havens that are very small countries where no or few consumers live.

I add the possibility for transfer pricing to the previous model ${ }^{22}$. Firms choose an intra-firm price $\phi$, which corresponds to the previous repatriation parameter. The interpretation of this parameter becomes obvious in the case of transfer pricing. This price can differ from the arm's

\footnotetext{
${ }^{22}$ I follow the model of transfer pricing in Davies et al. (2014).
} 
length price which is the price at which same firms would sell the same input to a third party. The intra-firm price defines the transfer pricing strategy that allows multinationals to shift profits towards tax havens. A high intra-firm price allows them to shift a large part of their profits. I do not model the firms' choice of their intra-firm price which depends on the corporate tax rate of the country and the concealment costs from shifting profits towards tax havens ${ }^{23}$. The intra-firm price is assumed to increase in the tax rate of the host country. A higher corporate tax rate in the host country leads firms to shift more profits in the tax haven.

I provide here a similar figure to Figure 2.1 in the first section. Firms can now locate part of their profits in a third country. The shaded areas represent the shares of total profits located in a tax haven that are assumed not to be redistributed to consumers.

Figure 7: Profits redistributed at Home

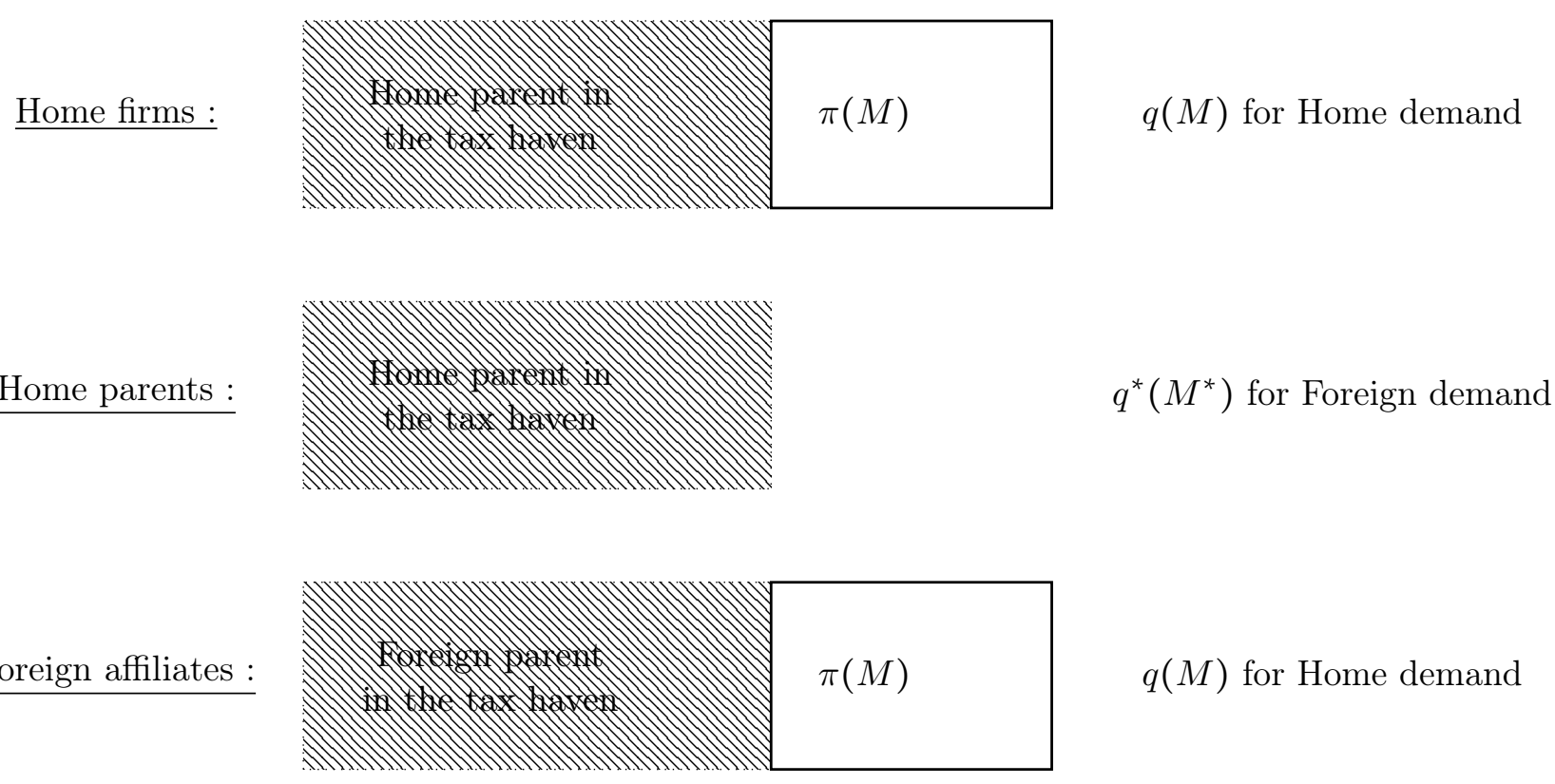

Similarly to the previous section, I find the equilibrium policies in the non-cooperative game without lobbying and then with lobbying in the grand coalition. In case of no lobbying, the government chooses the following policy:

$$
M_{0}^{\operatorname{tax}}=\frac{A-\phi}{\phi}
$$

For simplicity I only look at the case of equal valuations of contributions $(\gamma=1)$ which implies that the non-cooperative game equilibrium with bargaining in the grand coalition has a solution. The government chooses the following FDI policy:

$$
M^{G}=\frac{2(A-\phi)}{(\phi-z)-3(A-\phi)}
$$

\footnotetext{
${ }^{23}$ Firms that choose an intra-firm price different from the arm's length price have to incur a concealment cost. The concealment cost depends on the gap price only and is interpreted as the cost of hiring accountants or the fine that a firm pays when it is caught. It might vary across countries.
} 
Proposition 7 I can show that (i) the non-cooperative outcome without or with lobbying is always efficient and that (ii) free-entry is not the solution of the game without lobbying if the intra-firm price is high enough $\left(\phi \geq \frac{A}{2 M_{n}+1}\right)$.

In the previous sections, the externality problem is explained by the repatriation of profits which determines where profits are redistributed. The outcome is inefficient because governments do not consider the profits of their firms that are repatriated back home when choosing their entry policy. In a world with tax havens, the location of profits is the same for domestic firms and foreign affiliates. Governments then choose to restrict foreign entry and increase the profits of their domestic firms given that only a small part of the total profits made from domestic sales stay in the country. Given that most of the profits "disappear" in tax havens, governments choose restrictions that result from the trade-off between higher prices and higher revenues for consumers.

Previously I show that an agreement allows each government to take into account the domestic profits due to the presence of affiliates abroad. In the non-cooperative game these profits are not considered because they are located in tax havens. Governments only benefit from the profits from sales happening in their country and the policy of the other country does not affect the objective function of the government any more. Therefore an agreement has no role to play in a world with tax havens and foreign lobbying is the only channel to lower restrictions. However given that foreign affiliates shift a large part of their profits abroad foreign lobbying might not be able to lower restrictions.

Lemma 8 Tax treaties that increase the cost of shifting profits or curb tax havens are a first step towards agreements that reduce FDI barriers.

This result contributes to the debate on the effects of tax treaties on FDI. It defines a new role for tax treaties. Most of the literature (Blonigen et al. (2014)) has focused on the impact of tax treaties on FDI flows. The result 8 suggests that tax treaties are a first step for investment agreements to help countries reducing their FDI barriers. The proposition 7 states that the presence of tax havens makes the non-cooperative outcome Pareto-efficient and no agreement is necessary. Tax havens should be curbed or pricing transfer should become prohibitive in order to observe more agreements that help countries internalize the externality.

\section{Empirical analysis}

Following my theoretical results ${ }^{24}$ I test whether higher repatriation of profits increases foreign restrictions. Given the difficulty to quantify the repatriation behaviors of multinationals across countries and years, I use two proxies that cover the main determinants of the relocation of profits: corporate tax rates and future growth opportunities. I discuss the advantages and drawbacks of such proxies and show that they significantly affect the level of restrictions across countries, sectors and years. I finally discuss other possible channels that could explain this positive result.

\footnotetext{
${ }^{24}$ I do not test the predictions of my model regarding the impact of foreign lobbying on restrictions and whether an agreement is chosen or not in different situations.
} 


\subsection{Data}

The dependent variable is given by the level of foreign restrictions. I use two indexes that quantify FDI restrictions: the FDI Regulatory Restrictiveness Index (FDI Index) from the OECD and the Services Trade Restrictiveness Index (STRI) from the World Bank. The first index measures FDI restrictions in 58 countries, covers 22 sectors and is available for 8 years: 1997, 2003, 2006-2014. The second index covers 103 countries that represent all regions and income groups of the world. For each country, five major services sectors are covered: financial services (retail banking and insurance), telecommunications, retail distribution, transportation, professional services (accounting, auditing, and legal services). I focus on services that are characterized by high FDI barriers (Figures 10 and 11 in the Data Appendix). In addition Figure 12 shows that horizontal FDI is the main mode of trade in services. Part of the explanation is that many services are non-tradable and can not be provided through cross-border exports. Additional details are provided in the Data Appendix.

\subsubsection{Proxies for the repatriation of profits}

The literature suggests three determinants to explain the repatriation of profits by multinationals. ${ }^{25}$ The difference in corporate taxes and the existence of bilateral treaties on double taxation are the fiscal determinants of repatriation. Second growth opportunities in the host country determine whether profits are repatriated or reinvested in the host country. A last determinant is the existence of tax havens whose consequences are well described in Zucman (2014). In the previous parts I chose not to model the impact of these determinants on the $\phi$ parameter. I build two proxies for the behaviours of multinationals: a tax index and a growth index.

The Tax Index It quantifies the extent to which a country has a high level of taxes compared to other countries. Multinationals shift profits by comparing tax rates in their investment country and in their country of origin. More precisely the index quantifies the gap between the tax rate of a host country and the tax rates of the countries of origin of the multinationals. I use corporate tax rates data from the OECD that presents effective statutory tax rates taking into account integration or relief to reduce the effects of double taxation. A simple average across foreign countries loses a lot of information. I therefore use weights on tax rates such that countries with more or larger affiliates have more weight. However I only have FDI data per partner country at an aggregate level or FDI data per industry for the rest of the world. I therefore build two indexes and compare the results. I use inward FDI data at the country level when focusing on partner countries and outward FDI data at the industry level when focusing on industry data.

i) The tax index per industry: I here use data per industry. The world tax rate is the weighted average of tax rates for a representative vector of investing countries per industry and is the same for all countries. I use outward FDIs from all countries to build a world's representative investor in a given sector. I can compare a country tax index and the tax index of this world's representative investor of a given sector. The tax index for country $c(c \in W)$ and sector $s$

\footnotetext{
${ }^{25}$ Blonigen and Davies (2001) and Blonigen et al. (2014) for the bilateral treaties on double taxation and Overesch and Dreßler (2011), Hanlon et al. (2014), Zucman (2014) for the other determinants.
} 
is:

$$
\operatorname{Tax}_{c, s}=\tau_{c}-\tau_{s}^{W} \quad \text { with } \quad \tau_{s}^{W}=\frac{\sum_{j \in W} \tau_{j} F D I_{j, s}^{\text {out }}}{\sum_{j \in W} F D I_{j, s}^{\text {out }}}
$$

ii) The tax index per country: I here use data per partner country. Data of partner countries are not available per sector for confidentiality reasons. The world tax rate uses the inflows of FDI per partner country for all sector as weights. It reflects the composition of foreign investments in each country and now varies across countries but not across sectors. The Tax index for country $c$ is:

$$
\operatorname{Tax}_{c}=\tau_{c}-\tau_{c}^{W} \quad \text { with } \quad \tau_{c}^{W}=\frac{\sum_{j \in W_{-c}} \tau_{j} F D I_{j, c}^{i n}}{\sum_{j \in W_{-c}} F D I_{j, c}^{i n}}
$$

Repatriation of profits is assumed to be increasing in the tax proxy: $\operatorname{Corr}\left(\phi^{*}, \operatorname{Tax}\right) \geq 0$. The higher the tax rate in the host country compared to the rate in the country of origin, the more profits are repatriated home.

The growth opportunity Index In addition I build an index that reflects the growth opportunities of a country compared to those in the rest of the world. It complements the tax index. The higher the growth rate compared to a world average, the more profits made by foreign affiliates are not repatriated and are invested in the host country. The growth index is defined as the difference between the growth rate of a country and a world growth rate index. The world index is built as a weighted average of all countries' annual growth rate with the GDP of each country. The index for country $c$ and sector $s$ i:

$$
\text { Growth }_{c, s}=g_{c, s}-g_{c, s}^{W} \quad \text { with } \quad g_{c, s}^{W}=\frac{\sum_{j \in W} g_{j, s} G D P_{j, s}}{\sum_{j \in W} G D P_{j, s}}
$$

Repatriation of profits is assumed to be decreasing in the growth index: $\operatorname{Corr}\left(\phi^{*}\right.$, Growth $) \leq 0$

\subsection{Methodological issues}

There are methodological issues that emerge here. I have to address the endogeneity issue coming from the omitted variable bias and reverse causality. I address the first problem by adding other control variables such as GDP, GDP per capita, added-value per sector and previous binding commitments on restrictions. In addition I use a fixed-effect model for each specification. I add sector, year and country dummies depending on each case to the specification. I also add interaction dummies to test whether the result is robust. Second I address the reverse causality issue. Indeed lower restrictions can lead the government to lower tax rates. For example, a government could decide to lower the tax rate given that more firms are present. Multinationals could also exert pressure on governments to lower taxes. In order to solve for this problem I use lagged values for tax and growth rates. Another problem is the simultaneity bias. I assume that multinationals do not immediately react to a change in policies. An increase in restrictions might send a negative signal to multinationals that are expected to increase repatriation the next periods. I finally test the robustness of the results. I run a similar regression for different set of 
countries (OECD vs all countries), different FDI restrictions Index (OECD and WB Indexes) and for different years. After presenting the results of the regressions I discuss additional problems on how to interpret the results.

\subsection{Results}

I provide results for two cases and compare their results. First I use the OECD FDI restrictions Index which is available for all sectors but in a limited number of countries. Second I use the WB STR Index which is available for services only but for a larger number of countries.

FDI restrictions in all sectors I use here the FDI Index for OECD countries only. The specification is:

$$
R T_{c, s, t}=\alpha+\delta_{\tau} \operatorname{Tax}_{c, s, t}+\delta_{g} \text { Growth }_{c, s, t}+\lambda X+\delta_{c}+\delta_{t}+\delta_{s}+\delta_{c, s}+\delta_{t, s}+\epsilon_{c, s, t}
$$

with $\delta_{c}, \delta_{t}$ and $\delta_{s}$ the fixed effects for country $c$, at year $t$ and in sector $s$. $X$ is the set of control variables that gather here $\log \mathrm{GDP}$ and $\log \mathrm{GDP}$ per capita that are lagged by one period. The interaction fixed effects are the country-sector dummy $\delta_{c, s}$ and the year-sector dummy $\delta_{t, s}$. $R T$ is the level of FDI restrictions. Table 1 shows the results ${ }^{26}$.

Table 1: Impact of repatriation on FDI restrictions (OECD Index)

\begin{tabular}{|c|c|c|c|c|}
\hline & OLS with FE & OLS with FE & OLS with FE & OLS with Interaction FE \\
\hline TaxIndex & $\begin{array}{c}0.00482^{* * *} \\
{[0.00171]}\end{array}$ & & $\begin{array}{c}0.00460^{* * *} \\
{[0.00171]}\end{array}$ & $\begin{array}{c}0.00164^{* * *} \\
{[0.000399]}\end{array}$ \\
\hline GrowthIndex & & $\begin{array}{c}-0.0747 \\
{[0.0454]}\end{array}$ & $\begin{array}{c}-0.0642 \\
{[0.0456]}\end{array}$ & $\begin{array}{c}-0.0295^{* * *} \\
{[0.0106]}\end{array}$ \\
\hline $\operatorname{lag} \ln G d p$ & $\begin{array}{l}-0.213 \\
{[0.183]}\end{array}$ & $\begin{array}{c}-0.0934 \\
{[0.176]}\end{array}$ & $\begin{array}{l}-0.202 \\
{[0.184]}\end{array}$ & $\begin{array}{c}-0.283^{* * *} \\
{[0.0389]}\end{array}$ \\
\hline laglnGdpCap & $\begin{array}{c}0.174 \\
{[0.194]}\end{array}$ & $\begin{array}{l}0.0612 \\
{[0.187]}\end{array}$ & $\begin{array}{c}0.175 \\
{[0.194]}\end{array}$ & $\begin{array}{c}0.226^{* * *} \\
{[0.0408]}\end{array}$ \\
\hline Observations & 911 & 917 & 911 & 911 \\
\hline Country FE & Yes & Yes & Yes & Yes \\
\hline Sector FE & Yes & Yes & Yes & Yes \\
\hline Year FE & Yes & Yes & Yes & Yes \\
\hline Country*Sector FE & No & No & No & Yes \\
\hline Sector*Year FE & No & No & No & Yes \\
\hline R-sq & 0.399 & 0.394 & 0.400 & 0.981 \\
\hline
\end{tabular}

Standard errors in brackets

${ }^{*} p<0.1,{ }^{* *} p<0.05,{ }^{* * *} p<0.01$

Table 1 shows that the tax index significantly affects the level of FDI restrictions for all specifications. It is worth noting that it remains significant in the last specification with interaction dummies that capture most of the country-time-sector variations. The positive coefficient

\footnotetext{
${ }^{26}$ I here show results for the tax index per industry. Similar results are obtained using the tax index per country.
} 
on the tax index means that higher taxes relative to the rest of the world (more repatriation) leads to higher FDI restrictions. The negative coefficient on the growth index means that higher growth opportunities (less repatriation) leads to lower FDI restrictions. This is in line with my theoretical results.

FDI restrictions in services I now focus on FDI restrictions in the services sectors and use the WB STR Index. I use the AMNE/OECD database that describe foreign affiliates characteristics (number of employees, sales etc.) in each OECD country. I use services industries from the STRI database: banking, insurance, telecom, retailing, maritime, transport and legal services. Whereas the STRI index is available for a large number of countries over the world, the foreign affiliates database (AMNE) is only available for OECD countries. I start by restricting my analysis to OECD countries in order to be able to use the AMNE database then I consider all countries from the STRI database and use outward FDI data from the World Bank. The STRI database only provides one-year data. I use 2008 data for the tax and growth rates. I build the tax index by using the number of employees in foreign affiliates as a measure of foreign presence and add country and sector-specific dummies. Following Barattieri et al. (2015), other control variables are added such as Gdp, Gdp per capita, the level of GATS commitments (STRIur) and the value added in the manufacturing and in the services sectors. GATS commitments capture the possibilities for government to increase restrictions or not. The specification that is tested is:

$$
S T R I_{c, s}=\alpha+\delta_{\tau} \operatorname{Tax}_{c, s}+\delta_{g} \text { Growth }_{c, s}+\lambda X+\delta_{c}+\delta_{s}+\epsilon_{c, s}
$$

with $\delta_{c}$ and $\delta_{s}$ the fixed effects for country c and for sector s. STRI is the Services Trade Restrictiveness Index per country $c$ and per sector $s$. A similar regression with the tax index per industry is added in Appendix 8.2.

Results from Table 6.3 are similar to the previous results and support the model. I also observe that GATS commitments made in 1995 are a strong determinant of current restrictions. This is mainly explained by sectors for which governments committed to remove all kinds of restrictions. The index is then equal to zero and remains at zero. The tax index has therefore no impact on the level of restrictions. Countries with higher GDP per capita have lower levels of restrictions. GDP has a rather positive impact on foreign restrictions. Bigger countries have higher restrictions.

FDI restrictions in all countries I here keep all 103 countries from the STRI database. I cannot use the previous tax index. I then use the aggregate FDI outflows data of the World Bank as well as GDP, tax and FDI data from 2006. This part provides a broader picture and takes into account countries with very high restrictions such as emerging economies (China, Russia, Indonesia, India, Brazil, etc). I get similar results on the impact of repatriation. Second I focus on the complementary between the tax Index and the growth Index. The set of countries is more heterogenous. I add an interaction term between the two proxies and compute the marginal effect of the tax Index on FDI restrictions for different Growth Index. The marginal effect in Table 8 is:

$$
\frac{\partial S T R I_{c, s}}{\partial \operatorname{Tax}_{c}}=\delta_{g}+\gamma \text { Growth }_{c}
$$


Table 2: Impact of repatriation on services restrictions (STRI) for OECD countries using Partner country data

\begin{tabular}{lcccc}
\hline \hline & & Sector dummy & Country dummy & The two dummies \\
\hline TaxIndex & $0.00420^{* * *}$ & $0.00250^{* * *}$ & $0.00638^{* * *}$ & $0.00487^{* * *}$ \\
& {$[0.000986]$} & {$[0.000617]$} & {$[0.00109]$} & {$[0.00100]$} \\
GrowthInd & & $-0.0122^{*}$ & $-0.0280^{* *}$ & $-0.0162^{*}$ \\
& & {$[0.00652]$} & {$[0.0109]$} & {$[0.00932]$} \\
lnGdpCap & $-0.0944^{* * *}$ & -0.00458 & $-0.148^{* * *}$ & $-0.0785^{* * *}$ \\
& {$[0.0306]$} & {$[0.0191]$} & {$[0.0316]$} & {$[0.0256]$} \\
lnGdp & 0.0196 & -0.00456 & $0.0441^{* * *}$ & 0.0175 \\
& {$[0.0119]$} & {$[0.00837]$} & {$[0.0133]$} & {$[0.0117]$} \\
Striur & $0.533^{* * *}$ & $0.535^{* * *}$ & $0.442^{* * *}$ & $0.533^{* * *}$ \\
& {$[0.0562]$} & {$[0.0506]$} & {$[0.0233]$} & {$[0.0562]$} \\
VA_serv & $0.0222^{* * *}$ & $0.0225^{* * *}$ & $0.0314^{* * *}$ & $0.0213^{* * *}$ \\
& {$[0.00408]$} & {$[0.00392]$} & {$[0.00697]$} & {$[0.00595]$} \\
VA_manuf & $0.0212^{* * *}$ & $0.0239^{* * *}$ & $0.0387^{* * *}$ & $0.0217^{* * *}$ \\
& {$[0.00349]$} & {$[0.00350]$} & {$[0.00388]$} & {$[0.00344]$} \\
\hline Observations & 244 & 244 & 244 & 244 \\
Country Dummy & Yes & No & Yes & Yes \\
Sector Dummy & Yes & Yes & No & Yes \\
R-sq & 0.911 & 0.883 & 0.824 & 0.911 \\
\hline \hline
\end{tabular}

Standard errors in brackets

${ }^{*} p<0.1,{ }^{* *} p<0.05,{ }^{* * *} p<0.01$

Figure 8 shows that the marginal effect of the tax index for different levels of the growth Index. It shows that high tax rates on profits increase foreign restrictions only for positive relative growth rates. This means that the two indexes are complementary. Multinationals decide whether to shift profits for tax reasons only if there are growth opportunities in the host country. Without growth opportunities, multinationals repatriate their profits for any tax rate. The decision to repatriate is based on both the corporate tax rates and the growth opportunities of a country. This implies that my mechanism particularly applies for fast-growing emerging economies for which the level of tax rates determines the levels of restrictions.

\subsection{Discussion}

Wherether this result shows causality can be discussed. The primary objective of this past is to show that the data go in the direction of the mechanism explained in the paper. However a limited access to the data at stake in the paper restricts our empirical analysis. The role of the repatriation of profits as the channel at stake behind this result cab also be discussed. Other channels could be candidates for explaining this positive result. For example increasing taxes creates a disadvantage for domestic firms that should then be protected against foreign competition through higher restrictions. This channel is relevant for trade through exports across 


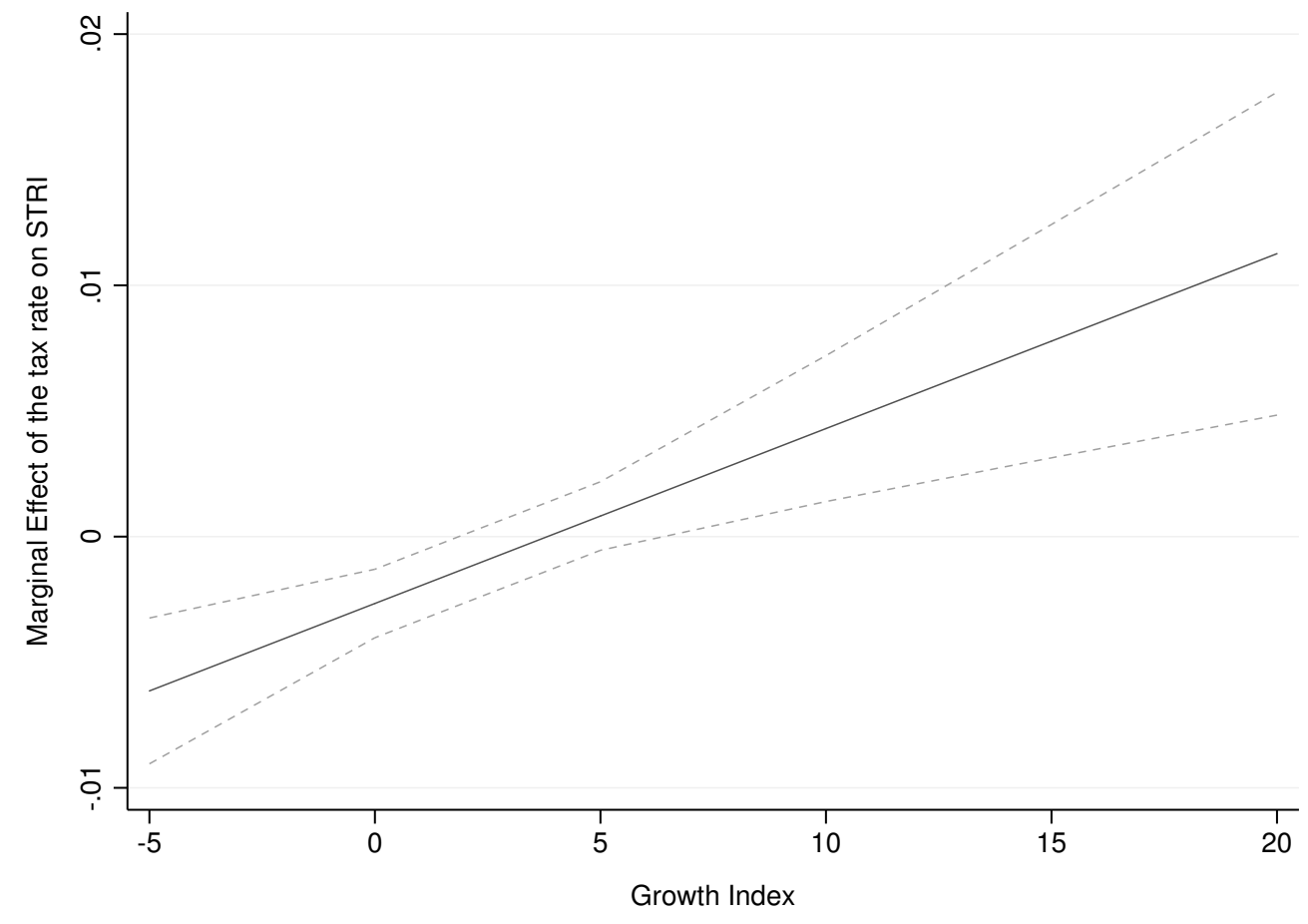

Figure 8: Complementarity between the tax and the growth indexes.

borders but is not in this model of horizontal FDI. Foreign affiliates and domestic firms face the same conditions to sell and produce. An increase in tax rates affect both domestic and foreign firms. However increasing corporate tax rates does not create a disadvantage for the domestic firms compared to their foreign competitors. Another candidate is the quality of political institutions that can act as a third factor and explain both lower tax rates and lower restrictions. This applies to countries with weak institutional levels. In certain cases, an improvement in the political institutions or in the quality of politicians can lead to less "expropriation" through corporate taxes ${ }^{27}$ and at the same time more opening to foreign investment. The profit shifting channel is not needed. The addition of country dummies or year-country dummies is however supposed to capture these political differences across countries.

A drawback of this empirical work is due to the data used for the tax rates index. Special tax provisions as an incentive to promote a policy are difficult to take into account. It is particularly relevant for FDI given the increasing number of special economic zones in emerging or developing economies. These zones provide better economic conditions (administrative simplifications, low tax rates, etc) to attract FDIs. There exist studies that have tried to measure multinationals' effective tax rates. They use backward-looking approaches and firm-level data. However these effective rates take into account both statutory provisions to provide certain incentives and aggressive tax planning strategies. It is difficult to determine which factor explains most of the lower effective tax rates. Using tax rates that already reflect tax planning strategies is counterproductive for this work. They also cannot be used as a proxy for profit shifting for

\footnotetext{
${ }^{27}$ This statement obviously does not apply to OECD countries in which high corporate taxes can not be called expropriation.
} 
the reason that they encompass governments' incentives to attract FDI. OECD (2013) reports that the use of different methodologies to calculate these effective tax rates result in divergent conclusions about the level of taxation imposed on multinationals. Using corporate tax rates from the OECD database seems to be a good approximation. In this paper it is the difference between all tax rates that matter, not the level of a tax rate in itself.

\section{Conclusion}

This paper rationalizes why barriers to FDI exist and why few agreements to reduce FDI barriers have been signed. First I show that the possibility for multinationals to repatriate their profits is a motive for restrictions. However these profits are not taken into account by governments that noncooperatively choose their FDI policies. Investment agreements can help countries to internalize this externality. However I show that foreign lobbying can make an agreement unnecessary if the repatriation of profits is limited and the government's valuation of foreign contributions high enough. Finally the presence of tax havens where part of the profits disappear and are not taken into account by governments always makes agreements unnecessary. Tax treaties that curb tax havens are a first step for agreements to reduce FDI barriers.

Additional work needs to be done to quantify the effects of foreign restrictions and the potential welfare gains from removing these barriers. Using the methods of Ossa (2014) I plan to build a model I could bring to the data and quantify the welfare effects of removing these barriers. The gains from services agreements that are currently negotiated could also be quantified. More empirical work should also be done to compare the influence of foreign lobbying across countries and industries. Some countries restrict foreign influence. There is no index that attempts to quantify the legal and informal barriers that restrain the capacity of foreign lobbies to exert an influence on governments. Another line of further research is the links between tax havens (tax treaties) and investment agreements. Few papers study the effect of tax havens on economic policies. More work should be done to see how profit shifting affects economic policies other than the revenues from tax collection. Taxes affect the behaviors of multinationals and their strategy in terms of profit shifting. It would be interesting to study whether current agreements that aim at reducing profit shifting towards tax havens affect the choice of FDI policies. 


\section{References}

Aidt, Toke S. and Uk Hwang, "To Ban or Not to Ban: Foreign Lobbying and Cross-National Externalities," Canadian Journal of Economics, February 2014, 47 (1), 272-297.

Aidt, T.S. and U. Hwang, "One Cheer for Foreign Lobbying," Cambridge Working Papers in Economics, December 2008, (0860).

Antràs, Pol and Gerard Padró i Miquel, "Foreign influence and welfare," Journal of International Economics, July 2011, 84 (2), 135-148.

Arnold, Jens M., Beata S. Javorcikb, and Aaditya Mattoo, "Does services liberalization benefit manufacturing firms? Evidence from the Czech Republic," Journal of International Economics, 2011, 85, 136-146.

Atalay, Enghin, Ali Horta?su, and Chad Syverson, "Vertical Integration and Input Flows," American Economic Review, 2014, 104 (4), 1120-48.

Bagwell, Kyle and Robert Staiger, "The economic theory of the GATT," American Economic Review, 1999, pp. 215-248.

Blanchard, Emily, "Reevaluating the Role of Trade Agreements:Does Investment Globalization Make the WTO Obsolete?," Journal of International Economics, 2010, 82, 63-72.

Blonigen, Bruce A. and Ronald B. Davies, "Do Bilateral Tax Treaties Promote Foreign Direct Investment?," SSRN Scholarly Paper ID 445964, Social Science Research Network, Rochester, NY June 2001.

_ and _, "The Effects of Bilateral Tax Treaties on U.S. FDI Activity," International Tax and Public Finance, September 2004, 11 (5), 601-622.

_ , Lindsay Oldenski, and Nicholas Sly, "The Differential Effects of Bilateral Tax Treaties," American Economic Journal: Economic Policy, May 2014, 6 (2), 1-18.

Bombardini, Matilde, "Firm heterogeneity and lobby participation," Journal of International Economics, July 2008, 75 (2), 329-348.

Borchert, Ingo, Batshur Gootiiz, and Aaditya Mattoo, "Policy Barriers to International Trade in Services: Evidence from a New Database," World Bank Policy Research Working Paper 6109, 2012.

Brander, James A., "Intra-industry trade in identical commodities," Journal of International Economics, February 1981, 11 (1), 1-14.

Compte, Olivier and Philippe Jehiel, "The coalitional Nash bargaining solution," Econometrica, 2010, 78 (5), 1593-1623.

Conconi, Paola, "Green lobbies and transboundary pollution in large open economies," Journal of International Economics, March 2003, 59 (2), 399-422.

Corrado, Anthony, Thomas Mann, Daniel Ortiz, Trevor Potter, and Frank Sorauf, Campaign Finance Reform: A Sourcebook, Washington: Brookings Institution Press, 1997.

Davies, Ronald B., "Tax Treaties and Foreign Direct Investment: Potential versus Performance," International Tax and Public Finance, November 2004, 11 (6), 775-802.

_ , Julien Martin, Mathieu Parenti, and Farid Toubal, "Knocking on Tax Haven's Door: Multinational Firms and Transfer Pricing," CESifo Working Paper Series 5132, CESifo Group Munich 2014. 
di Giovanni, Julian, "What drives capital flows? The case of cross-border M\&A activity and financial deepening," Journal of International Economics, January 2005, 65 (1), 127-149.

Fernandes, Ana M. and Caroline Paunov, "Foreign direct investment in services and manufacturing productivity: Evidence for Chile," Journal of Development Economics, 2012, 97 (2), 305-321.

Fiorini, Matteo and Mathilde Lebrand, "The political economy of services trade agreements," 2016.

Gawande, By Kishore, Pravin Krishna, and Marcelo Olarreaga, "Lobbying Competition Over Trade Policy," International Economic Review, 2012, 53 (1), 115-132.

Gawande, Kishore, Pravin Krishna, and Michael J. Robbins, "Foreign Lobbies and U.S. Trade Policy," The Review of Economics and Statistics, 2006, 88 (3), 563-571.

_, William Maloney, and Gabriel Montes-Rojas, "Foreign informational lobbying can enhance tourism: Evidence from the Caribbean," Journal of Development Economics, 2009, 90 (2), 267-275.

Grossman, Gene and Elhanan Helpman, "Protection for Sale," American Economic Review, September 1994, 84, 833-850.

_ and _., "Trade Wars and Trade Talks," Journal of Political Economy, August 1995, 103, $675-708$.

Hanlon, Michelle, Rebecca Lester, and Rodrigo S. Verdi, "The Effect of Repatriation Tax Costs on U.S. Multinational Investment," SSRN Scholarly Paper ID 2441529, Social Science Research Network, Rochester, NY May 2014.

Javorcik, Beata, Wolfgang Keller, and James Tybout, "Openness and Industrial Response in a Wal-Mart World: A Case Study of Mexican Soaps, Detergents and Surfactant Producers," The World Economy, 2008, 31 (12), 1558-1580.

Jensen, J.Bradford, Global Trade in Services: Fear, Facts, and Offshoring, Peterson Institute for International Economics, 2011.

Johnson, Harry G, "Optimum Tariffs and Retaliation," Rev. Econ. Studies, 1953-54, 21 (2), $142-53$.

Maggi, Giovanni and Andres Rodriguez-Clare, "The Value of Trade Agreements in the Presence of Political Pressures," Journal of Political Economy, 1998, 106 (3), 574-601.

_ and _ , "A Political-Economy Theory of Trade Agreements," American Economic Review, 2007, 97 (4), 1374-1406.

Mrazova, Monika, "Trade negotiations when market access matters," September 2009.

_ , "Trade Agreements when Profits Matter," September 2011.

OECD, Addressing Base Erosion and Profit Shifting, Paris: Organisation for Economic Cooperation and Development, February 2013.

Ossa, Ralph, "A "New Trade" Theory of GATT/WTO Negotiations," Journal of Political Economy, February 2011, 119 (1), 122-152.

_ , "Trade Wars and Trade Talks with Data," American Economic Review, December 2014, 104 (12), 4104-4146. 
Overesch, Michael and Daniel Dreßler, "The Impact of Tax Treaties and Repatriation Taxes on FDI Revisited," 2011.

Vicard, V., "Profit shifting through transfer pricing: evidence from French firm level trade data," Working paper 555, Banque de France 2015.

Zucman, Gabriel, "Taxing across Borders: Tracking Personal Wealth and Corporate Profits," Journal of Economic Perspectives, 2014, 28 (4), 121-48. 


\section{Appendix}

\subsection{Data}

The FDI Regulatory Restrictiveness Index (OECD) This index measures restrictions on FDI in 58 countries, covers 22 sectors and is available for 8 years: 1997, 2003, 2006-2014. The OECD lists the main types of restrictions that the index covers: foreign equity limitations, screening or approval mechanisms, restrictions on the employment of foreigners and operational restrictions. The index is between 0 and 1 with high values for high restrictions. Figure 8.1 shows a high variance across sectors and across countries. The following figure 10 focuses on barriers

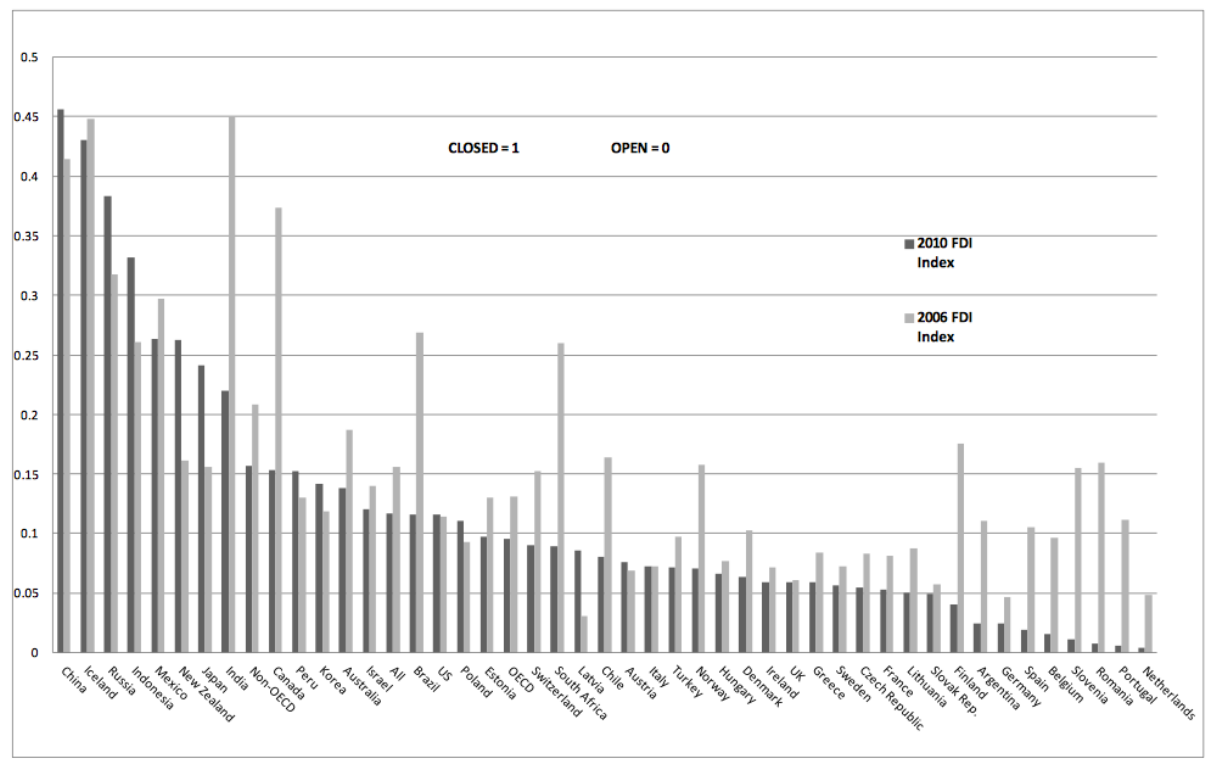

Figure 9: FDI restrictions' variations across countries and years (Source: OECD).

to FDI across services industries and across countries using the OECD FDI restriction Index. Several sectors are very restricted (real estate investment, media, maritime) whereas others are mostly not restricted (hotels and restaurants, wholesale, architectural). In addition restrictions vary across countries. Canada, the USA and Germany have on average low restrictions to foreign entry whereas China, India and Indonesia still have restrictive policies in most of the services sectors.

The Services Trade Restrictiveness Index (World Bank) It covers 103 countries that represent all regions and income groups of the world. For each country, five major services sectors are covered: financial services ( retail banking and insurance), telecommunications, retail distribution, transportation, professional services (accounting, auditing, and legal services). The four modes of supplying services are covered. In the rest of the paper I only keep the data for mode 3, which is trade through commercial presence. Policies are categorized with associated scores: completely open (0), virtually open but with minor restrictions (25), major restrictions (50), virtually closed with limited opportunities to enter and operate (75), and completely closed (100). Figure 11 shows the difference in FDI barriers across countries. 
FDI Regulation Restrictiveness Index

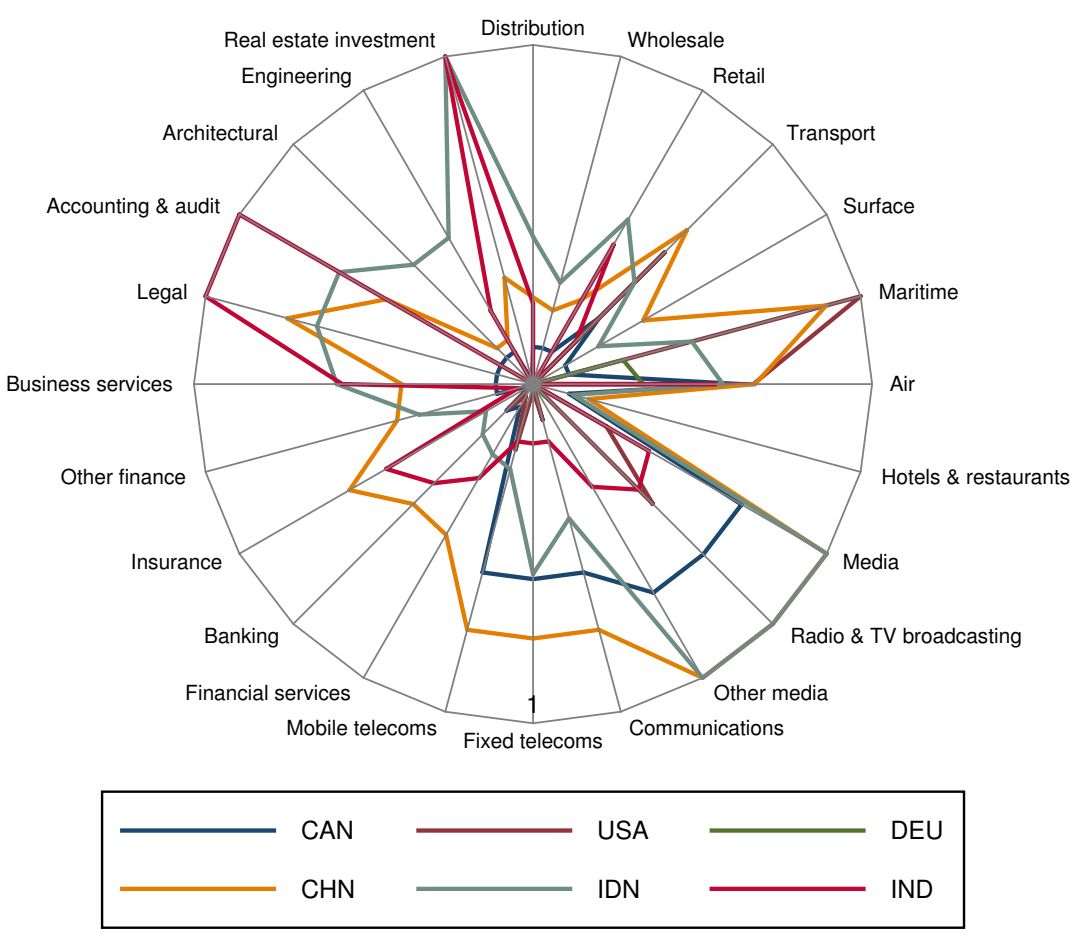

Center is at 0

Figure 10: Barriers to FDI per services industries and per country. Source of the data: OECD

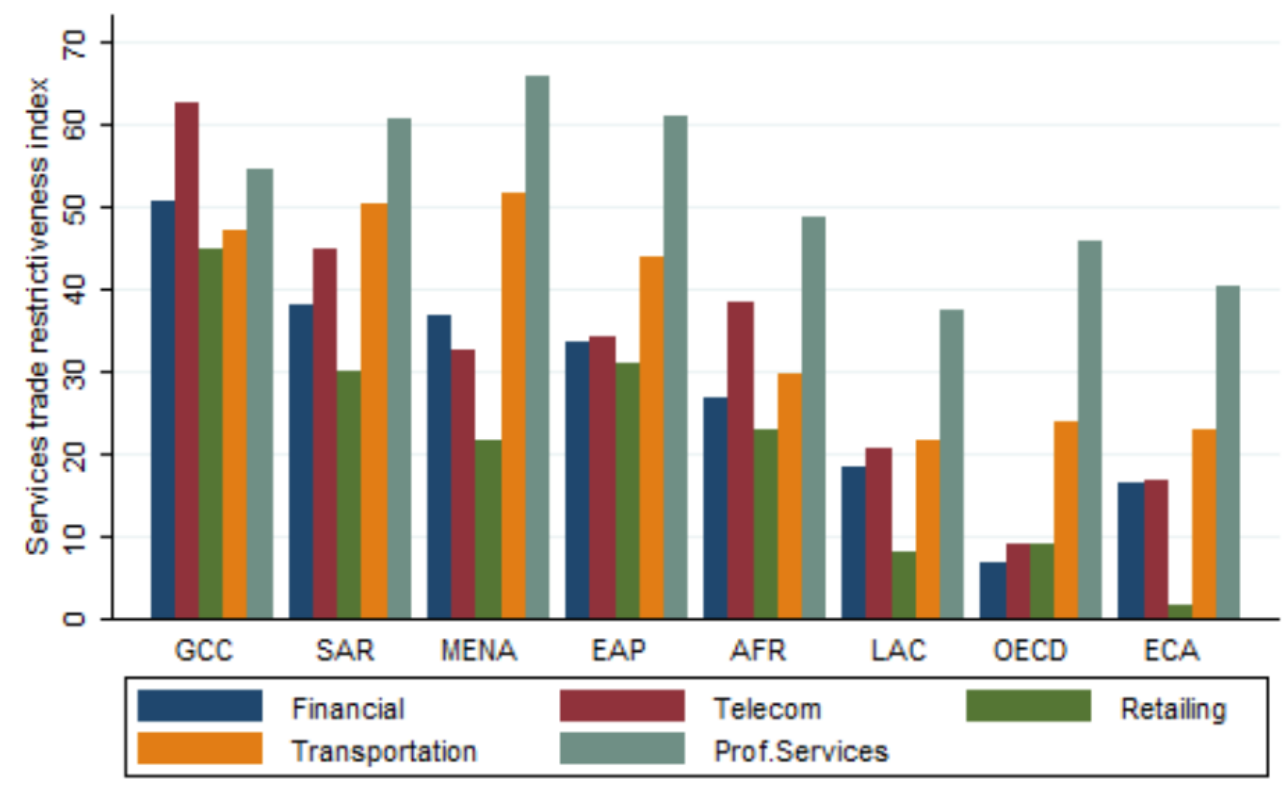

Note: 103 countries included.

Figure 11: Services trade restrictiveness index by sector and region. Source: Borchert et al. (2012) 
Services sectors Figures 12 and 13 show that horizontal FDI is the main mode of trade for services. Many services can only be provided in the host country through commercial presence and cannot be exported. The first figure shows that commercial presence is the main mode of services exports and imports. In addition commercial presence in services sector has been growing over the last years.

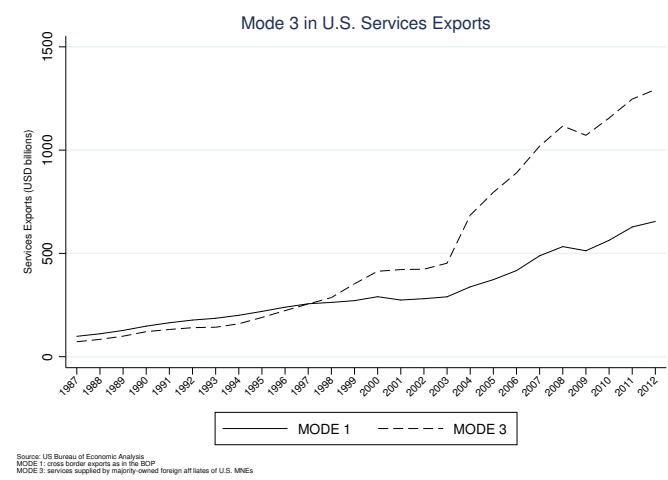

Figure 12: Commercial presence (mode 3) is the Figure 13: Commercial presence (mode 3) is the major mode of services exports and imports in the US.

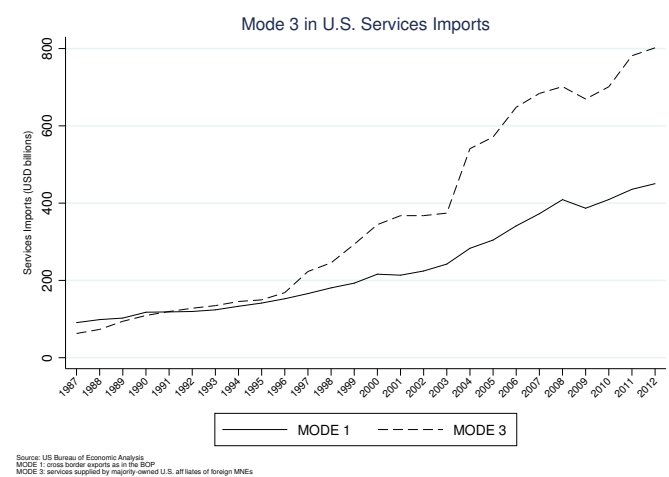

major mode of services exports and imports in the US.

\subsection{Additional empirical analysis}

Restrictions in services sectors I provide results for the two types of tax index I describe: the tax index per industry with outflows data in the following Table 8.2 and the tax index per country with partner data in Table 6.3. Similar results are obtained.

Table 3: Impact of repatriation on services restrictions (STRI) using outflows at the industry level

\begin{tabular}{|c|c|c|c|c|c|c|}
\hline & est1 & est2 & est3 & est4 & est5 & est6 \\
\hline \multirow[t]{2}{*}{ TaxIndex } & $0.0299^{* * *}$ & $0.00224^{* *}$ & & & $0.00222^{* *}$ & $0.0299^{* * x}$ \\
\hline & {$[0.00650]$} & {$[0.00112]$} & & & {$[0.00112]$} & {$[0.00650]$} \\
\hline \multirow[t]{2}{*}{ GrowthInd } & & & $-0.0117^{* *}$ & $-0.00675^{* *}$ & -0.00753 & $-0.0138^{* *}$ \\
\hline & & & {$[0.00482]$} & {$[0.00335]$} & {$[0.00500]$} & {$[0.00680]$} \\
\hline \multirow[t]{2}{*}{$\operatorname{lnGdp}$} & $-0.416^{* * *}$ & 0.00193 & 0.00510 & $0.0116^{*}$ & 0.00668 & $0.0675^{* *}$ \\
\hline & {$[0.101]$} & {$[0.0118]$} & {$[0.0144]$} & {$[0.00605]$} & {$[0.0122]$} & {$[0.0292]$} \\
\hline \multirow[t]{2}{*}{$\operatorname{lnGdpCap}$} & $0.770^{* * *}$ & 0.0266 & 0.0207 & 0.0206 & 0.0298 & $-0.231^{* * *}$ \\
\hline & {$[0.197]$} & {$[0.0279]$} & [0.0400] & [0.0183] & {$[0.0278]$} & {$[0.0769]$} \\
\hline \multirow[t]{2}{*}{ Striur } & $0.362^{* * *}$ & $0.580^{* * *}$ & $0.390^{* * *}$ & $0.672^{* * *}$ & $0.597^{* * *}$ & $0.362^{* * *}$ \\
\hline & [0.0330] & [0.0839] & {$[0.0227]$} & {$[0.0512]$} & {$[0.0843]$} & {$[0.0330]$} \\
\hline Observations & 123 & 123 & 291 & 291 & 123 & 123 \\
\hline Country Dummy & Yes & No & Yes & No & No & Yes \\
\hline Industry Dummy & No & Yes & No & Yes & Yes & No \\
\hline R-sq & 0.649 & 0.712 & 0.560 & 0.706 & 0.718 & 0.649 \\
\hline
\end{tabular}

Standard errors in brackets

${ }^{*} p<0.1,{ }^{* *} p<0.05,{ }^{* * *} p<0.01$ 


\subsection{Appendix - Figures from the Model section}

I here provide simulations to see the effect on FDI policies and joint surpluses of three variables: the government's valuation of foreign contributions, the repatriation of profits, and the number of national firms. This is useful to characterize cases when bargaining in the grand coalition has no solution such that a sub-coalition is formed. 

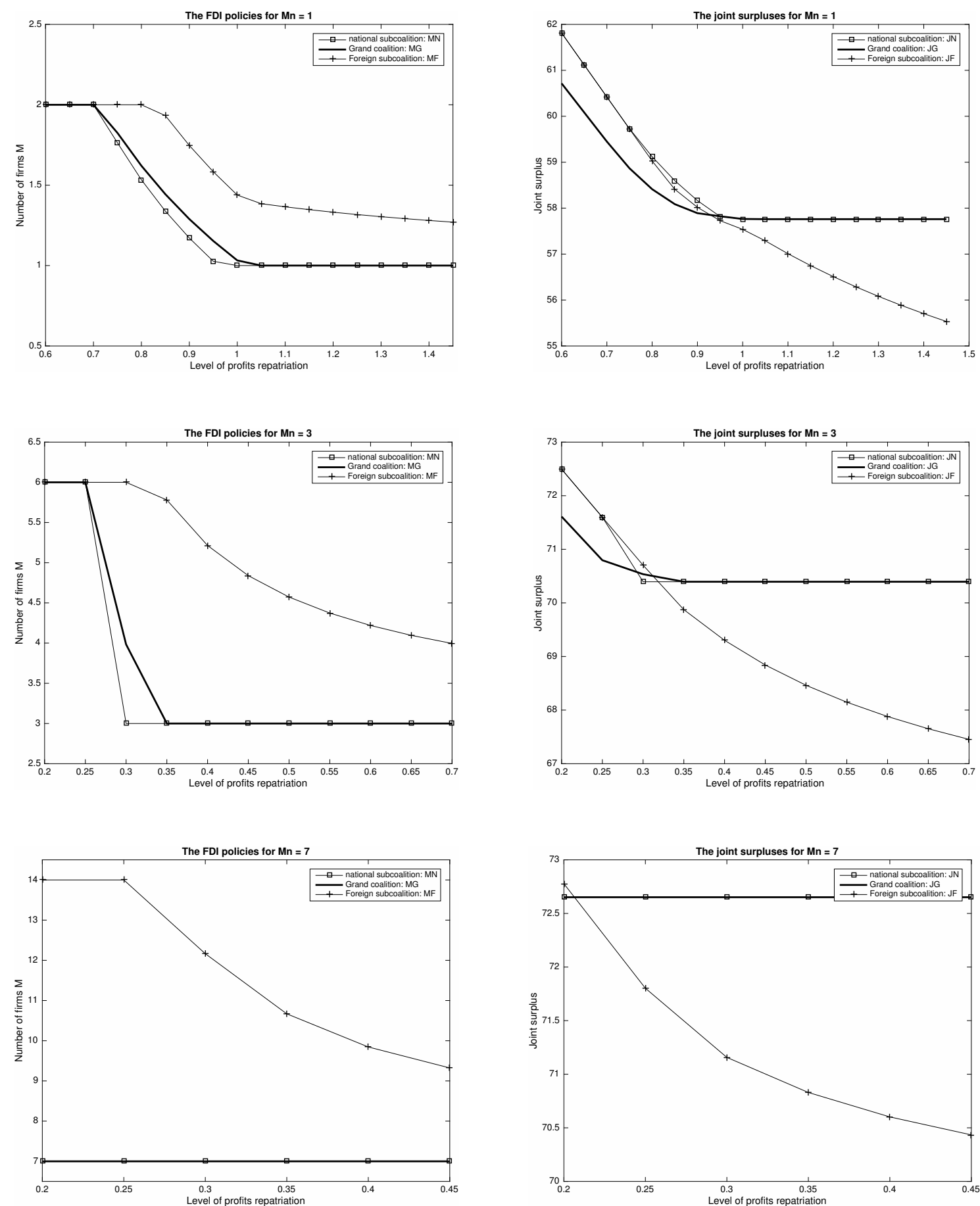

Figure 14: Effect of repatriation on FDI policies $\left\{M^{N}, M^{G}, M^{F}\right\}$ and joint surpluses $\left\{J^{N}+\right.$ $\left.\Pi^{* f}, J^{G}, J^{F}+\Pi\right\}$ for different numbers of national firms $M_{n}\left(M_{n} \in\{1,3,7\}\right) .{ }^{29}$ 

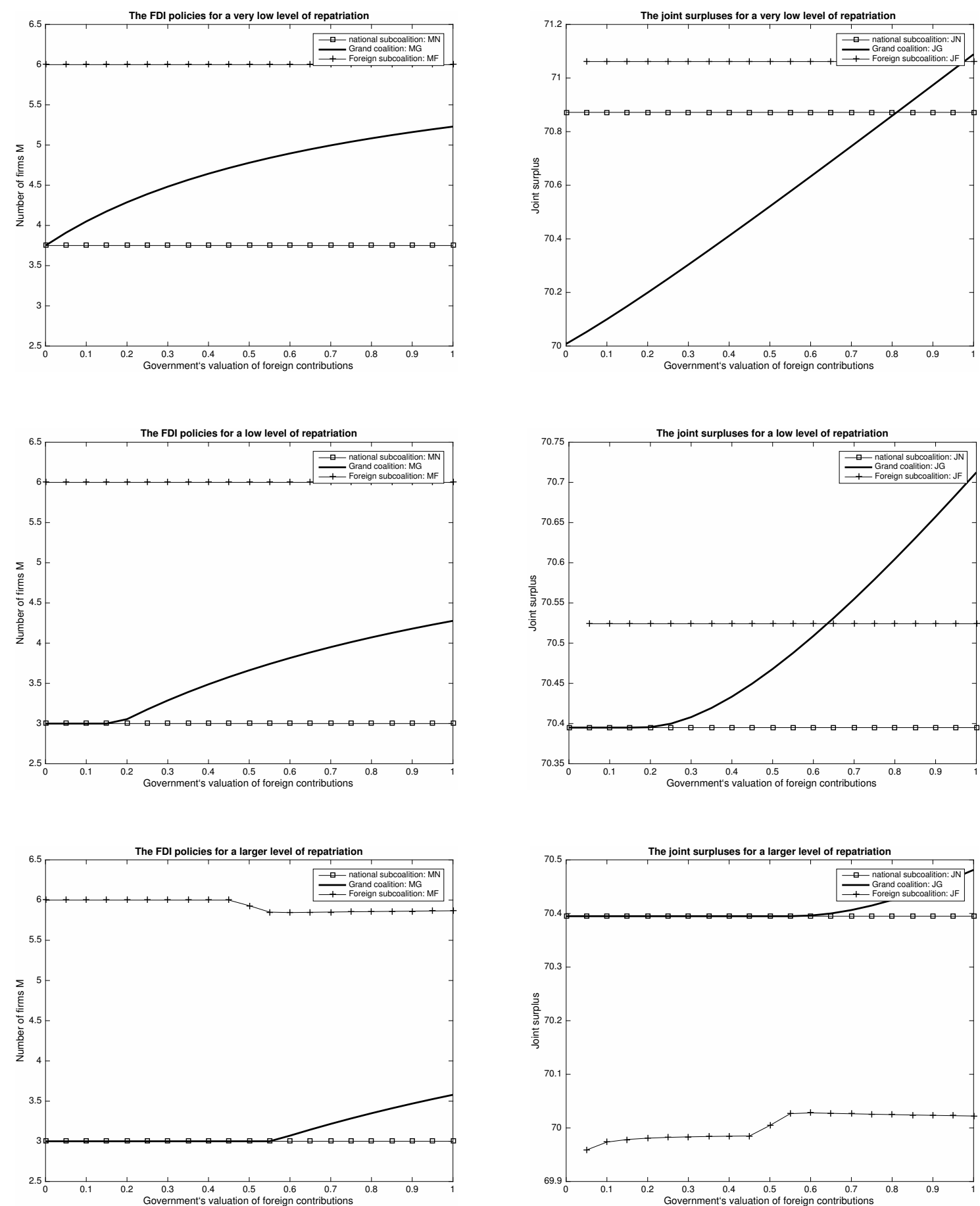

Figure 15: Effect of undervaluation of foreign contributions $\left\{M^{N}, M^{G}, M^{F}\right\}$ and joint surpluses $\left\{J^{N}+\Pi^{* f}, J^{G}, J^{F}+\Pi\right\}$ for different levels of repatriation. 

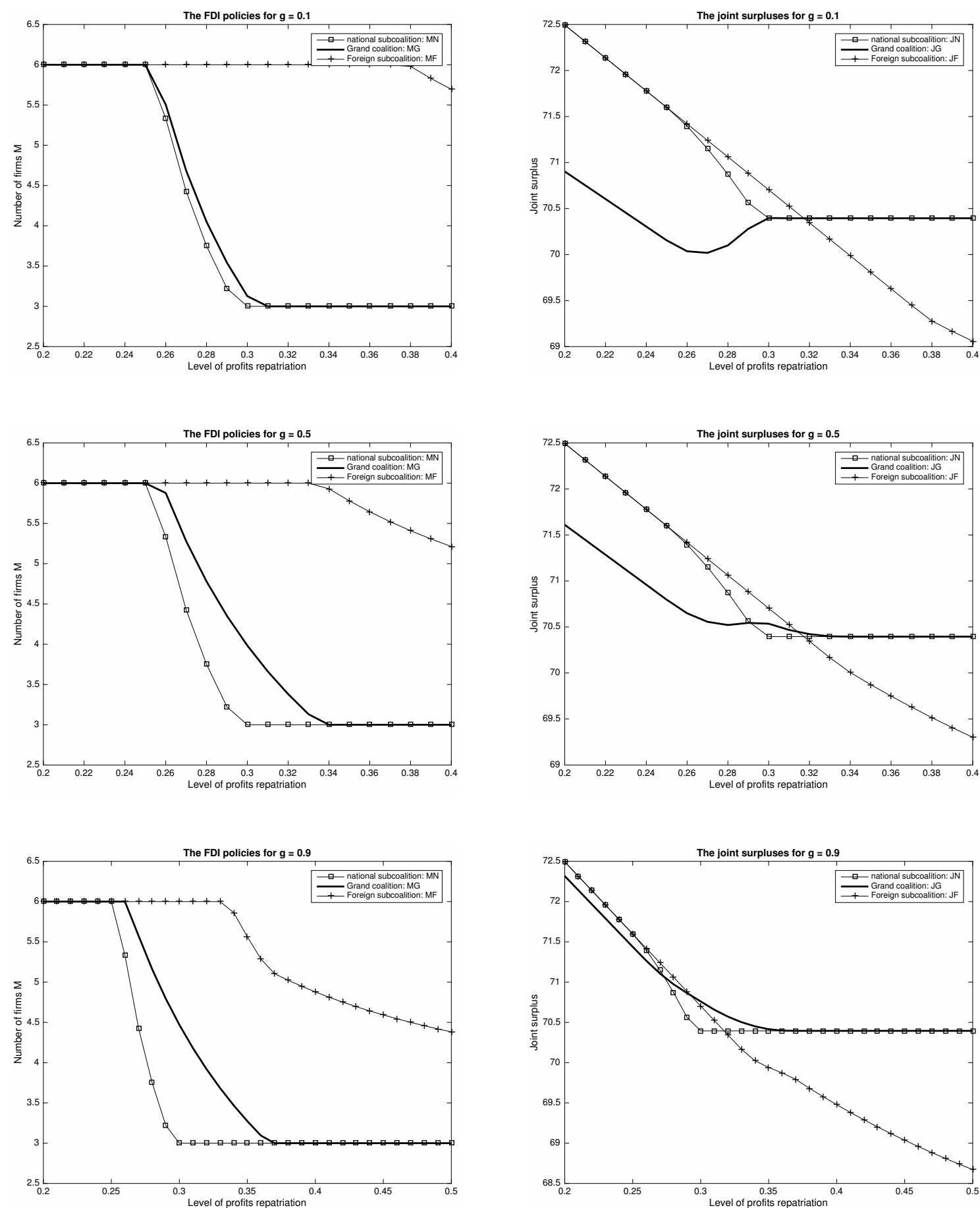

Figure 16: Effect of repatriation on FDI policies $\left\{M^{N}, M^{G}, M^{F}\right\}$ and joint surpluses $\left\{J^{N}+\right.$ $\left.\Pi^{* f}, J^{G}, J^{F}+\Pi\right\}$ for different valuations of foreign contributions $\gamma \in\{0.1,0.5,0.9\}$. 


\subsection{Proofs}

\subsubsection{Proofs Section 3}

Proof of Lemma 1 The solution of the government's maximisation problem for any $\delta$ is

$$
M_{0}(\delta)=-\frac{(A-z)(2-\delta)((1-\delta)(3 / 2-\delta)+1)+(z-\phi)(2-\delta)\left(2+\delta\left(M_{n}-1\right)\right)}{(A-z) \delta[(\delta-3) / 2+(2-\delta)(3-2 \delta)]+(z-\phi) \delta\left(2+\delta\left(M_{n}-1\right)\right)}
$$

given the constraint $M_{n} \leq M_{0}(\delta) \leq 2 M_{n}$

Proof of Proposition 1 The Pareto-efficient solution is given by

$$
\left(M_{+}, M_{+}^{*}\right)=\underset{M}{\operatorname{argmax}} W\left(M, M^{*}\right)+W\left(M^{*}, M\right)
$$

and $M_{+}=M_{+}^{*}=2 M_{n}$. I can show that $M_{0}<M_{+}$except if $M_{0}=2 M_{n}$. The outcome in the non-cooperative game is inefficient.

Proof of Lemma 3 I show here that the policies in the grand coalition all maximise the total surplus. I prove it given that the surplus now depends on the size of the foreign contributions and the allocations can be binding. I need to prove that the outcome $M$ defined in the maximisation of the Nash product by

$$
a W^{\prime}\left(M^{G}, M^{*}\right)+\Pi^{\prime}\left(M^{G}\right)+\gamma \Pi^{\prime}\left(M^{G}\right)=0
$$

is the solution that maximises the joint surplus $\mathbb{J}^{G}$ that is defined by:

$$
\mathbb{J}^{G}(M)=a W\left(M, M^{\star}\right)+(\gamma-1) c^{f}+\Pi(M)+\Pi^{\star f}(M)
$$

The difficulty is due to the presence of $c^{f}$ in the joint surplus $\mathbb{J}^{G}$. I need to find the expression of $c^{f}$ in order to state the efficiency of the Nash product maximisation. There are several cases that appear because of the additional constraints of possible deviations from each of the two lobbies.

1. The constraints that prevent deviations from the two sub-coalitions are not binding.

I show that the policies that maximize the Nash product maximize the total surplus. The policy $M$ is defined in equation 8.1 and the contributions are defined by the allocation of the surplus depending on each bargaining power. At the equilibrium the allocation is given by:

$$
\left\{\begin{aligned}
a W\left(M, M^{*}\right)+c+\gamma c^{f}-G_{0}= & \sigma^{G}\left[\mathbb{J}^{G}-G_{0}-L_{0}-L_{0}^{f}\right] \\
\Pi(M)-c-L_{0}= & \sigma^{D}\left[\mathbb{J}^{G}-G_{0}-L_{0}-L_{0}^{f}\right] \\
\Pi^{* f}(M)-c^{f}-L_{0}^{f}= & \sigma^{F}\left[\mathbb{J}^{G}-G_{0}-L_{0}-L_{0}^{f}\right]
\end{aligned}\right.
$$

I find the expression of $c^{f}$ at the equilibrium and replace it in the joint surplus from equation 8.2 :

$$
\begin{aligned}
\mathbb{J}^{G}(M) & =a W\left(M, M^{*}\right)+(\gamma-1) c^{f}+\Pi(M)+\Pi^{* f}(M) \\
\Rightarrow \quad \mathbb{J}^{G}(M) & =\frac{1}{1+\sigma^{F}(\gamma-1)}\left[a W\left(M, M^{*}\right)+\Pi(M)+\gamma \Pi^{* f}(M)\right]+\text { cte }
\end{aligned}
$$

This shows that the policy $M$ that maximises the Nash product in equation 8.1 is the same as the one that maximises the joint surplus from 8.2 given the expression of the contribution $c^{f}$ in terms of $\mathrm{M}$. 
2. The constraint that defines the deviation of the national sub-coalition is binding.

When a constraint binds, the allocation in 8.3 does not apply any more. The contribution of the national lobby and the policy $M$ have to be such that the national lobby does not want to deviate. The binding constraint is given by

$$
\begin{aligned}
a W\left(M, M^{*}\right)+\gamma c^{f}+\Pi(M) & =\mathbb{J}^{D}\left(M^{D}, M^{*}\right) \\
\Rightarrow \gamma c^{f} & =\mathbb{J}^{D}\left(M^{D}, M^{*}\right)-a W\left(M, M^{*}\right)-\Pi(M)
\end{aligned}
$$

The expression of $c^{f}$ is then reported in equation 8.2:

$$
\begin{aligned}
\mathbb{J}^{G}(M) & =a W\left(M, M^{*}\right)+(\gamma-1) c^{f}+\Pi(M)+\Pi^{* f}(M) \\
\Rightarrow \gamma \mathbb{J}^{G}(M) & =a W\left(M, M^{*}\right)+\Pi(M)+\gamma \Pi^{* f}(M)+(\gamma-1) \mathbb{J}^{D}\left(M^{D}, M^{*}\right)
\end{aligned}
$$

Similarly to the previous case, this proof shows that the policy M that maximises the Nash product in equation 8.1 is the same as the one that maximises the joint surplus from 8.2.

3. The constraint that defines the deviation of the foreign sub-coalition is binding. The binding constraint is given by

$$
a W\left(M, M^{*}\right)+c+(\gamma-1) c^{f}+\Pi^{* f}(M)=\mathbb{J}^{F}\left(M^{F}, M^{*}\right)
$$

This comes from the undervaluation of foreign contributions. The maximization problem implies that the foreign contribution should decrease whereas the national contribution should increase till the other constraint is binding. In that case the reasoning of the previous point applies.

Proof of Proposition 2 : Allocations If the two sub-coalitions are binding,

$$
G\left(M^{G}, M^{\star C}, c^{G}, c^{f C}\right)=\mathbb{J}^{\mathbb{D}}+\mathbb{J}^{\mathbb{F}}-\mathbb{J}^{\mathbb{G}}
$$

The last case of the government's allocation being higher than the outside option happens when the two sub-coalitions are binding. The allocation is determined such that the two constraints are verified. It results in the following allocations for the three players:

$$
\left\{\begin{array} { l l } 
{ G ( . ) + L ( . ) } & { = \mathbb { J } ^ { \mathbb { D } } } \\
{ G ( . ) + L ^ { f } ( . ) } & { = \mathbb { J } ^ { \mathbb { F } } } \\
{ G ( . ) + L ( . ) + L ^ { f } ( . ) } & { = \mathbb { J } ^ { \mathbb { G } } }
\end{array} \Leftrightarrow \left\{\begin{array}{l}
G(.)=\mathbb{J}^{\mathbb{D}}+\mathbb{J}^{\mathbb{F}}-\mathbb{J}^{\mathbb{G}} \\
L(.)=\mathbb{J}^{\mathbb{G}}-\mathbb{J}^{\mathbb{F}} \\
L^{f}(.)=\mathbb{J}^{\mathbb{G}}-\mathbb{J}^{\mathbb{D}}
\end{array}\right.\right.
$$

with $\mathbb{J}^{\mathbb{D}}$ the joint surplus of the national sub-coalition, $\mathbb{J}^{\mathbb{F}}$ the joint surplus of the national subcoalition, and $\mathbb{J}^{\mathbb{G}}$ the joint surplus of the grand coalition .

Proof of Proposition 7 I show here that the total surplus functions differ depending in which sub-coalition is formed. This implies that the sub-coalition policy can maximize the total surplus without being equal to the grand coalition policy. In the case of $\gamma=1$, all surplus functions are equal and the grand coalition policy is the one that maximizes the total surplus.

The total surplus in the grand coalition is given by:

$$
\mathbb{J}^{G}\left(M, M^{*}\right)=\frac{1}{1+\sigma^{F}(\gamma-1)}\left[a W\left(M, M^{*}\right)+\Pi(M)+\gamma \Pi^{* f}\right]+\frac{(\gamma-1)}{1+\sigma^{F}(\gamma-1)}\left[-\sigma^{F}\left(G_{0}+L_{0}\right)+\left(1-\sigma^{F}\right) L_{0}^{f}\right]
$$

The total surplus in the foreign-subcoalition is given by:

$$
\mathbb{J}^{\mathbb{F}}\left(M^{F}, M^{*}\right)+\Pi(M)=\frac{1}{\gamma\left(1-\sigma_{G}\right)+\sigma_{G}}\left[a W\left(M^{F}, M^{*}\right)+\gamma \Pi^{* f}\left(M^{F}\right)\right]+\Pi\left(M^{F}\right)+\frac{(\gamma-1)\left[\left(1-\sigma_{G}\right) G_{0}+\sigma_{G} L_{0}^{f}\right]}{\gamma\left(1-\sigma_{G}\right)+\sigma_{G}}
$$

The total surplus in the national sub-coalition is given by:

$$
\mathbb{J}^{D}\left(M, M^{*}\right)+\Pi^{* f}(M)=a W\left(M, M^{*}\right)+\Pi(M)+\Pi^{\star f}(M)
$$


Proof of Proposition 7 : Policies The expressions of the policies for $\gamma \neq 1$ are given by

$$
\begin{aligned}
& M^{G}=M^{\star G}=\min \left(2 M_{n}, \max \left(\frac{(A-z)(\gamma-2) M_{n}+(z-\phi) a M_{n}+(A-\phi)\left(\gamma\left(1+M_{n}\right)+a\right)}{(A-z) \gamma+\left(1+M_{n}\right)(a+\gamma)(\phi-z)}, M_{n}\right)\right) \\
& M^{D}=M^{\star D}=\min \left(2 M_{n}, \max \left(\frac{a\left[(A-\phi)-M_{n}(\phi-z)\right]-2 M_{n}(A-z)}{a\left(1+M_{n}\right)(\phi-z)}, M_{n}\right)\right) \\
& M^{F}=M^{\star F}=\min \left(2 M_{n}, \max \left(\frac{A\left[\gamma\left(1+2 M_{n}\right)+a\right]+M_{n}(a-\gamma) z-\phi\left(1+M_{n}\right)(a+\gamma)}{\gamma(A-z)+\left(1+M_{n}\right)(a+\gamma)(\phi-z)}, M_{n}\right)\right)
\end{aligned}
$$

Proof of Proposition 7 : Efficiency I show here that the policies in the foreign sub-coalition maximise the total surplus. I prove it given that the surplus now depends on the size of the foreign contributions and the allocations can be binding.

I define the surplus of the two players $\mathbb{J}^{F}\left(M, M^{*}\right)=a W\left(M, M^{*}\right)+(\gamma-1) c^{f}+\Pi^{* f}(M)$.

$$
\begin{aligned}
a W\left(M, M^{*}\right)+\gamma c^{f}-G_{0} & =\sigma_{G}\left[\mathbb{J}^{F}(M)-G_{0}-L_{0}^{f}\right] \\
\Pi^{* f}(M)-c^{f}-L_{0}^{f} & =\left(1-\sigma_{G}\right)\left[\mathbb{J}^{F}(M)-G_{0}-L_{0}^{f}\right]
\end{aligned}
$$

Finally I can show that the total surplus for the three players when the government and the foreign lobby play the political bargaining game is:

$$
\begin{aligned}
\mathbb{J}^{F}\left(M^{F}, M^{*}\right)+\Pi\left(M^{F}\right) & =\frac{1}{\gamma\left(1-\sigma_{G}\right)+\sigma_{G}}\left[a W\left(M^{F}, M^{*}\right)+\gamma \Pi^{* f}\left(M^{F}\right)\right] \\
& +\Pi\left(M^{F}\right)+\frac{(\gamma-1)\left[\left(1-\sigma_{G}\right) G_{0}+\sigma_{G} L_{0}^{f}\right]}{\gamma\left(1-\sigma_{G}\right)+\sigma_{G}}
\end{aligned}
$$

Proof of lemma 4 I show that $\frac{\partial M^{G}}{\partial \gamma}$ can be written as a second-degree polynomial of the variable $M_{n}$ such that $\frac{\partial M^{G}}{\partial \gamma}=\alpha M_{n}^{2}+\beta M_{n}+\delta$. Given that $\alpha=2(A-z)(\phi-z)(a+2)>0$, I can conclude that either $\frac{\partial M^{G}}{\partial \gamma} \geq 0$ for all $M_{n}$ or there exists two solutions $M_{n, 1}$ and $M_{n, 2}$ such that $\frac{\partial M^{G}}{\partial \gamma}=0$ and $\frac{\partial M^{G}}{\partial \gamma} \geq 0$ for $M_{n} \leq M_{n, 1}$ and $M_{n} \geq M_{n, 2}$. For simplicity, I only consider $M_{n, 2}$ in the last case. Therefor there exists a $\tilde{M}_{n}$ such that $\frac{\partial M^{G}}{\partial \gamma}=0$ and such that

$$
M_{n} \leq \tilde{M}_{n} \Rightarrow \frac{\partial M^{G}}{\partial \gamma} \leq 0 \quad \wedge \quad M_{n} \geq \tilde{M}_{n} \Rightarrow \frac{\partial M^{G}}{\partial \gamma} \geq 0
$$

Proof of Proposition 4 In order to prove the second part, I need to show that the joint surplus $J^{G}$ in the grand coalition is increasing in the government's valuation $\gamma$.

$$
\begin{aligned}
& J^{G}=a W\left(M^{G}, M^{*}\right)+(\gamma-1) c^{f, G}+\Pi\left(M^{G}\right)+\Pi^{* f}\left(M^{G}\right) \\
& \Rightarrow \frac{\partial J^{G}}{\partial \gamma}=\frac{\partial a W\left(M^{G}, M^{*}\right)}{\partial \gamma}+c^{f, G}+(\gamma-1) \frac{\partial c^{f, G}}{\partial \gamma}+\frac{\partial \Pi\left(M^{G}\right)}{\partial \gamma}+\frac{\partial \Pi^{* f}\left(M^{G}\right)}{\partial \gamma} \\
& \text { with } \quad \frac{\partial c^{f, G}}{\partial \gamma}=-\sigma^{F} \frac{\partial J^{G}}{\partial \gamma}+\frac{\partial \Pi^{* f}\left(M^{G}\right)}{\partial M} \text { from } 8.3 \\
& \Rightarrow \quad \frac{\partial J^{G}}{\partial \gamma}\left[1+\sigma^{F}(\gamma-1)\right]=c^{f, G}+\underbrace{\left[\frac{\partial a W\left(M^{G}, M^{*}\right)}{\partial M}+\frac{\partial \Pi\left(M^{G}\right)}{\partial M}+\gamma \frac{\partial \Pi^{* f}\left(M^{G}\right)}{\partial M}\right]}_{=0} \frac{\partial M^{G}}{\partial \gamma} \\
& \Rightarrow \quad \frac{\partial J^{G}}{\partial \gamma} \geq 0 \quad\left(\forall \gamma \in(0,1), \quad 1+\sigma^{F}(\gamma-1) \geq 0\right)
\end{aligned}
$$

In addition we always have $J^{G}(\gamma=1)>J^{D}(\gamma=1), J^{D}(\gamma=1)$. Therefore $\gamma^{\text {sub }}>0$ if $J^{G}(\gamma=0)<J^{D}(\gamma=1)$ or $J^{G}(\gamma=0)<J^{D}(\gamma=0)$ (proof of existence for some cases from simulation exercices in Annex). 


\subsubsection{Proofs Section 4}

Proof of Proposition 1 This results from the restriction in Lemma 4 such that $\frac{\partial M^{G}}{\partial \gamma}$ and Result 5 according to which $M^{D}<M^{G}<M^{F}$. 